\title{
Chronic Alcohol Consumption and Withdrawal Do Not Induce Cell Death in the Suprachiasmatic Nucleus, But Lead to Irreversible Depression of Peptide Immunoreactivity and mRNA Levels
}

\author{
M. D. Madeira, ${ }^{1}$ J. P. Andrade, ${ }^{1}$ A. R. Lieberman, ${ }^{2}$ N. Sousa, ${ }^{1}$ O. F. X. Almeida, ${ }^{3}$ and M. M. Paula-Barbosa ${ }^{1}$ \\ ${ }^{1}$ Department of Anatomy, Porto Medical School, 4200 Porto, Portugal, ${ }^{2}$ Department of Anatomy and Developmental \\ Biology, University College London, London WC1E 6BT, United Kingdom, and ${ }^{3}$ Max-Planck-Institute of Psychiatry, \\ Clinical Institute, D-W-80804 Munich, Germany
}

\begin{abstract}
There is evidence that chronic ethanol treatment (CET) disrupts the biological rhythms of various brain functions and behaviors. Because the suprachiasmatic nucleus (SCN) is widely recognized as the dominant pacemaker of the circadian system, we have examined the effects of CET and withdrawal on the main morphological features and chemoarchitecture of this hypothalamic nucleus. Groups of rats ethanol-treated for 6 and 12 months were compared with withdrawn rats (ethanol-treated for 6 months and then switched to a normal diet for an additional 6 months) and with groups of age-matched control and pair-fed control rats. The volume and the total number of neurons of the SCN were estimated from conventionally stained material, whereas the total number of astrocytes and of neurons containing vasopressin (AVP), vasoactive intestinal polypeptide (VIP), gastrin-releasing peptide (GRP), and somatostatin (SS) were estimated from immunostained sections. The estimates were obtained using unbiased stereological methods, based on Cavalieri's principle and the optical fractionator.
\end{abstract}

Despite the widely accepted view that chronic alcohol abuse affects virtually the entire CNS, in the past decades the main research focus has been on alterations that might explain the alcohol-induced cognitive dysfunctions. Notwithstanding this fact, there is abundant clinical and experimental data indicating that chronic ethanol treatment (CET) is associated with endocrine dysfunction (Morgan, 1982). Studies performed in humans are not conclusive regarding the severity of these disturbances, and in this respect investigations carried out in rodents have provided a major contribution to the understanding of the effects of alcohol on the functioning of the nervous and endocrine systems. In these species, CET is known to depress the activity of the systems involved in the production of thyroid hormones (Mason et al., 1992) and gonadal steroids (Cicero et al., 1979; Rivier et al., 1992) and to activate the hypothalamic-pituitary-adrenal axis (Tabakoff et al., 1978; Rivier et al., 1990; Rivier, 1996). Yet, despite extensive knowledge concerning hormonal disturbances associated with excess alcohol, it remains unclear whether these alterations result

Received Sept. 3, 1996; revised Nov. 11, 1996; accepted Dec. 3, 1996.

This work was supported by Junta Nacional de Investigação Científica e Tecnológica, Project PECS/C/SAU/92/95 and Unit 121/94. We thank Professor C. Sunkel for assistance with densitometry evaluations, Professor A. Cadete-Leite for constructive advice, and Mr. A. Pereira and Mr. Alameda Alfaia for excellent technical assistance.

Correspondence should be addressed to Maria Dulce Madeira, Department of Anatomy, Porto Medical School, Alameda Hernâni Monteiro, 4200 Porto, Portugal. Copyright (C) 1997 Society for Neuroscience $0270-6474 / 97 / 171302-18 \$ 05.00 / 0$
The volume of the SCN and the total number of SCN neurons and astrocytes did not vary among groups. We found, however, that CET induced a significant reduction in the total number of AVP-, VIP-, GRP-, and SS-containing neurons. Withdrawal from alcohol did not reduce but rather augmented the loss of VIP- and GRP-immunoreactive neurons. The CET-induced neurochemical alterations seem to result from a decrease in neuropeptide synthesis, as revealed by the reduction in AVP and VIP mRNA levels demonstrated by in situ hybridization with radioactively labeled 48-mer AVP and 30-mer VIP probes. It is thus possible to conclude that the irreversible CET-induced changes in the neurochemistry of the SCN might underpin the disturbances in circadian rhythms observed after long-term alcohol consumption.

Key words: suprachiasmatic nucleus; chronic ethanol intake; withdrawal; AVP; VIP; GRP; somatostatin; stereology; immunocytochemistry; in situ hybridization from direct effects of alcohol at the level of the hypothalamus, the pituitary, or the peripheral endocrine glands.

Some of the functions that are modulated by the neuroendocrine system and are known to be altered by CET display (under normal conditions) typical biological rhythms, which are themselves affected by exposure to alcohol. For example, the circadian variations in plasma corticosterone concentration (Tabakoff et al., 1978) and the cyclic pattern of gonadotrophin production in females (Sundberg et al., 1987; Alfonso et al., 1993) are both abolished as a consequence of CET. In addition, excess alcohol affects the biological rhythms inherent in other behaviors and functions, leading, for example, to disruption of circadian sleep rhythms (Gilliam and Collins, 1983; Hilakivi et al., 1987), to interference with spontaneous locomotor activity (Deimling and Schnell, 1980), and to changes in patterns of feeding and drinking (Miller, 1992).

There is strong evidence that the establishment of biological rhythms and the entrainment of rhythms to environmental light/ dark cycles are governed by the suprachiasmatic nucleus (SCN) (Klein et al., 1991). The SCN of the rat is a relatively small nucleus that contains 17,000 parvocellular neurons of uniform size (Madeira et al., 1995). These neurons, however, are not distributed evenly throughout the nucleus but display regional differences in packing density and orientation (van den Pol, 1980), which have led to the recognition of distinct anatomical subdivisions within the SCN, the dorsomedial and the ventrolateral, which also differ 
Table 1. Mean body and brain weights of control, pair-fed control, ethanol-treated, and withdrawn rats, at 8 and 14 months of age

\begin{tabular}{|c|c|c|c|c|}
\hline & Controls (C) & $\begin{array}{l}\text { Pair-fed } \\
\text { controls (PFC) }\end{array}$ & $\begin{array}{l}\text { Ethanol-treated } \\
\text { rats }(\mathrm{ET})\end{array}$ & $\begin{array}{l}\text { Withdrawn rats } \\
\text { (W) }\end{array}$ \\
\hline \multicolumn{5}{|l|}{ Body weight } \\
\hline 8 months old & $570(0.12)$ & $443(0.09)$ & $432(0.06)$ & - \\
\hline 14 months old & $635(0.08)$ & $503(0.06)$ & $505(0.15)$ & $586(0.11)$ \\
\hline \multicolumn{5}{|l|}{ Brain weight } \\
\hline 8 months old & $1.54(0.02)$ & $1.51(0.04)$ & $1.49(0.08)$ & - \\
\hline 14 months old & $1.63(0.08)$ & $1.54(0.03)$ & $1.54(0.07)$ & $1.57(0.09)$ \\
\hline
\end{tabular}





with respect to their connections (van den Pol and Dudek, 1993; Morin, 1994) and the peptides they produce (Card and Moore, 1984; van den Pol and Tsujimoto, 1985). Neurons synthesizing vasopressin (AVP) and somatostatin (SS) are concentrated in the dorsomedial subdivision, whereas those producing vasoactive intestinal polypeptide (VIP) and gastrin-releasing peptide (GRP) are located in the ventrolateral subdivision. The neurons of the latter subdivision receive the bulk of afferents to the SCN and together with AVP-producing neurons give rise to efferents to extra- and intrahypothalamic target areas through which the SCN influences various functions and behaviors.

Previous studies have shown that experimentally induced lesions of the SCN or bilateral ablations of the SCN abolish the rhythmicity of corticosterone production, sleep-wakefulness, feeding patterns, and locomotor activity, and completely eliminate the phasic release of gonadotrophins (for reviews, see Rusak and Zucker, 1979; Moore, 1983). Because the effects of alcohol exposure on the rhythmic patterns of certain functions and behaviors are identical to those resulting from lesions of the SCN, we have sought to establish whether the alterations induced by CET might be explained by changes in the SCN, such as specific alterations of its constituent neuronal and/or glial subpopulations. Using unbiased stereological techniques, we have estimated the volume and the total cell number of the SCN in rats exposed to alcohol over periods of 6 and 12 months. Because SCN astrocytes share many morphological (van den Pol, 1980) and functional (van den Pol et al., 1992; Prosser et al., 1994) features with SCN neurons, we have also separately estimated the total number of cells containing glial fibrillary acidic protein (GFAP). In addition, to further characterize the effects of CET on the cellular and molecular mechanisms underlying the expression of circadian rhythms, we have also independently estimated, using the same stereological techniques, the total number of the major neuronal subpopulations in the SCN, i.e., the AVP-, VIP-, GRP-, and SS-immunoreactive neurons. Because exposure to alcohol might interfere differentially with the synthesis, release, and metabolism of different peptides (Paula-Barbosa and Tavares, 1985; McLane, 1987; Ruela et al., 1994), we have also examined the consequences of CET on the expression of mRNA encoding AVP and VIP in the SCN by in situ hybridization. Finally, because there is evidence that the alcohol-induced disruption of the biological rhythms of certain functions and behaviors are normalized after abstinence from alcohol (Tabakoff et al., 1978; Anderson et al., 1985; Adinoff et al., 1990; Dees and Skelley, 1990), we have extended this study to the SCN of CET rats withdrawn from alcohol for 6 months.

A preliminary report of this work has been published previously in abstract form (Madeira et al., 1994).

\section{MATERIALS AND METHODS}

\section{Animals and treatments}

Male Wistar rats derived from the colony of the Gulbenkian Institute of Science (Oeiras, Portugal) were maintained throughout the experiment under standard laboratory conditions: $12 \mathrm{hr}$ light/dark cycle (lights on at 8:00 A.M.) and temperature of $22^{\circ} \mathrm{C}$. Food pellets and water were available ad libitum until the rats were 2 months old. At this age they were placed in individual cages, assigned to four experimental groups, and treated as follows.

Ethanol-treated subgroups. Rats were given an aqueous ethanol solution as their only available liquid source for 6 or 12 months, i.e., until the age of 8 or 14 months. The ethanol concentration started with a $5 \%(\mathrm{v} / \mathrm{v})$ solution and was increased progressively by $1 \%$ per day to a final $20 \%$ (v/v) solution 2 weeks later. Food was freely available throughout the treatment period. The amounts of food and ethanol solution consumed were measured every other day.

Withdrawal group. Rats were ethanol-treated for 6 months and then switched to tap water for an additional 6 months. The shift from ethanol treatment to water intake was performed gradually over a 2 week period by progressive reduction of the ethanol concentration in the drinking solution by $1 \%$ per day. Food pellets were freely available throughout the experiment.

Pair-fed control subgroups. Animals with free access to water were given for 6 or 12 months an amount of dry food that was equivalent to the mean amount of food consumed by animals of the ethanol-treated group plus an additional quantity that provided a caloric intake equal to that supplied by the quantity of ethanol solution drunk by the ethanol-treated rats. The additional number of pellets was calculated, taking into account the caloric value of ethanol $(1 \mathrm{gm}=7 \mathrm{Kcal})$ and the mean volume of alcohol consumed by ethanol-treated rats $(10 \mathrm{ml}$ ethanol $=7.9 \mathrm{gm})$. This nutritional control was chosen because in a previous study (Madeira et al., 1993) we demonstrated that it was adequate to overcome the hyperosmolality derived from the addition of sucrose or dextrin-maltose to the drinking solution, which is commonly used in alcohol research (Lieber and DeCarli, 1982).

Control subgroups. These animals had free access to standard laboratory diet and tap water for the duration of the study.

In all groups, liquids consumed were supplemented with $300 \mathrm{mg} / 100 \mathrm{ml}$ of vitamins (Vitamin Diet Fortification Mixture, ICN Biomedicals, Cleveland, $\mathrm{OH}$ ) and $500 \mathrm{mg} / 100 \mathrm{ml}$ of minerals (Salt Mixture, ICN Biomedicals). Body weights were recorded every 15 th day and on the day the animals were killed.

The material used in this investigation was collected between 9:00 A.M. and 10:00 A.M. from 95 animals. The hypothalami from 42 animals, ages 8 months (18) and 14 months (24), were embedded in glycolmethacrylate and used for the estimation of the volume of and total cell numbers in the SCN. Thirty-six rats, aged 14 months, were used for the immunocytochemical detection of the AVP-, VIP-, GRP-, and SS-containing neurons in the SCN. Ten 14-month-old rats were used for the identification and enumeration of SCN astrocytes by immunocytochemical detection of GFAP. Finally, seven animals, aged 14 months, were used for the analysis of AVP and VIP mRNA expression by in situ hybridization.

Blood alcohol determinations. Blood alcohol concentrations were measured in all ethanol-treated rats used in this experiment. Blood samples $(500 \mu \mathrm{l})$ were collected in the morning (8:00 A.M.) and evening (6:00 P.M.) from the dorsal vein of the tail after 4, 6, and 14 months of 
treatment. The blood ethanol concentrations were determined using an enzymatic assay kit (Boehringer Mannheim, Mannheim, Germany).

Hormone determinations. Corticosterone assays were carried out in 14-month-old control, ethanol-treated, and ethanol-withdrawn rats $15 \mathrm{~d}$ before they were killed. Blood samples $(500 \mu \mathrm{l})$ were taken from the dorsal vein of the tail at 2:00 A.M., 8:00 A.M., 2:00 P.M., and 8:00 P.M. The blood samples were placed in Eppendorf tubes, and serum was separated by centrifugation and preserved at $-20^{\circ} \mathrm{C}$ until the time of assay. Corticosterone levels were determined by radioimmunoassay using a kit supplied by ICN Biomedicals (Costa Mesa, CA). All samples were assayed in a single run, the intra-assay coefficient of variation being $\sim 5 \%$.

\section{Tissue preparation}

Conventional histological procedures. Animals were anesthetized with ether and transcardially perfused with a fixative solution containing $1 \%$ paraformaldehyde and $1 \%$ glutaraldehyde in $0.12 \mathrm{~m}$ phosphate buffer at $\mathrm{pH}$ 7.2. The brains were removed from the skulls, weighed, and post-fixed for $15 \mathrm{~d}$ in fresh fixative. After removal of the frontal and occipital poles, the blocks of tissue containing both the right and left hypothalami were dehydrated through a graded series of ethanol solutions and embedded in glycolmethacrylate (hydroxyethylmethacrylate; Technovit 7100, Kulzer and Co., Wehrheim, Germany), as described in detail elsewhere (West et al., 1991). These blocks were then sectioned in the coronal plane at a nominal thickness of $40 \mu \mathrm{m}$ using a Jung Multicut microtome. The sections were collected, mounted serially, and stained with a Giemsa solution modified for use in glycolmethacrylate-embedded material (West et al., 1991).

Immunohistochemical procedures. The animals were anesthetized by intraperitoneal injection of a solution of $2.5 \%$ sodium pentobarbital in physiological saline $(2 \mathrm{ml} / \mathrm{kg}$ body weight) and killed by transcardiac perfusion of fixative solution. For immunostaining with GFAP, the fixative used contained $4 \%$ paraformaldehyde and $0.1 \%$ glutaraldehyde in $0.12 \mathrm{M}$ phosphate buffer at $\mathrm{pH}$ 7.6. For immunostaining with antiserum against AVP, VIP, GRP, and SS, rats were perfused with a solution containing $4 \%$ paraformaldehyde in phosphate buffer at $\mathrm{pH}$ 7.6. The brains were removed and immersed for $24 \mathrm{hr}$ in the same fixative solution. After the frontal and occipital poles were trimmed away, blocks containing the right and left hypothalami were mounted on a vibratome and serially sectioned at a nominal thickness of $30 \mu \mathrm{m}$ in the coronal plane. Sections were collected in PBS, washed twice, and then treated with $3 \%$ $\mathrm{H}_{2} \mathrm{O}_{2}$ for 10 min to inactivate endogenous peroxidase.

For GFAP immunohistochemistry, all sections containing the SCN were incubated with a polyclonal rabbit antibody (Dakopatts, Glostrup, Denmark) diluted 1:250 in PBS containing 1\% Triton X-100 for $48 \mathrm{hr}$ at $4^{\circ} \mathrm{C}$. After three washes in PBS, sections were incubated with biotinylated goat anti-rabbit IgG (Vector Laboratories, Burlingame, CA) at a dilution of 1:400 for $2 \mathrm{hr}$ and with avidin-biotin peroxidase complex (Vectastain Elite ABC Kit, Vector Laboratories) at a dilution of 1:800 for $2 \mathrm{hr}$ at room temperature. Peroxidase was visualized using $0.05 \%$ diaminobenzidine (DAB) (Sigma, St. Louis, MO) as chromogen and $0.01 \% \mathrm{H}_{2} \mathrm{O}_{2}$ in PBS as substrate, for $10 \mathrm{~min}$. During this step, sections were incubated with $0.2 \%$ nickel ammonium sulfate to intensify the $\mathrm{DAB}$ reaction product. To enable precise visualization of the boundaries of the SCN, sections were counterstained with cresyl violet.

For peptide immunostaining, alternate sections were collected separately in PBS. From the two independent sets of sections thus obtained from each brain, one was used for AVP or VIP immunostaining and the other for GRP or SS immunostaining. Antisera against AVP, VIP, and GRP were a gift of Dr. Ruud Buijs (The Netherlands Institute for Brain Research, Amsterdam) and the antiserum against SS was purchased from Peninsula Laboratories (Belmont, CA). The antisera were used at the following dilutions: AVP, 1:5000; VIP, 1:1000; GRP, 1:5000; SS, 1:4000. Sections were incubated overnight with the primary antiserum at $4^{\circ} \mathrm{C}$. Biotinylated goat anti-rabbit antibody (Vector Laboratories) at 1:400 dilution was used as the secondary antibody. Sections were treated with avidin-biotin peroxidase complex (Vector Laboratories) diluted 1:800. In these two last steps, the incubation was carried out for at least $1 \mathrm{hr}$ at room temperature. After treatment with the peroxidase complex, sections were incubated for $10 \mathrm{~min}$ in DAB (Sigma), to which $0.01 \% \mathrm{H}_{2} \mathrm{O}_{2}$ was added. Sections were rinsed with PBS for at least $30 \mathrm{~min}$ between each step. Tissue penetration was increased by the inclusion of $1 \%$ Triton $\mathrm{X}-100$ in all immunoreactions and by sonication. To intensify the DAB reaction product, sections were incubated for $10 \mathrm{~min}$ and during the $\mathrm{DAB}$ step with $0.2 \%$ nickel ammonium sulfate. All procedures were performed on a rocking table. Stained sections were mounted on gelatin-coated slides and air-dried. They were then dehydrated and coverslipped using Eukitt. The immunohistochemical staining of the sections from all groups analyzed was performed in parallel at the same time. The same procedure was followed for control sections, which were incubated without primary antiserum; no immunostaining was observed in these sections.

AVP and VIP $m R N A$ in situ hybridization histochemistry. The rats were killed by decapitation. The entire brain was rapidly removed and immediately frozen in dry ice. The brain was then mounted in a Cryostat, and $12-\mu \mathrm{m}$-thick sections containing both the right and left hypothalami were cut in the coronal plane. Sections were then thaw-mounted onto gelatincoated slides, warmed to $37^{\circ} \mathrm{C}$ for $\sim 1$ min, and stored at $-70^{\circ} \mathrm{C}$ until use. Before hybridization, the slides were fixed in $4 \%$ formaldehyde in $0.12 \mathrm{M}$ PBS at $\mathrm{pH} 7.4$ for $5 \mathrm{~min}$ at room temperature, rinsed twice with PBS, incubated in $0.25 \%$ acetic anhydride in $0.1 \mathrm{M}$ triethanolamine $/ 0.9 \% \mathrm{NaCl}$ at $\mathrm{pH} 8$ for $10 \mathrm{~min}$ at room temperature, and passed through a graded series of ethanols and chloroform before being air-dried. Hybridizations were carried out under steady-state conditions overnight at $37^{\circ} \mathrm{C}$ with $0.5-1.0 \times 10^{6} \mathrm{dpm}$ of AVP and VIP probes in $25 \mu \mathrm{l}$ of a hybridization buffer described in detail elsewhere (Przewlocki et al., 1992). The AVP probe (MWG-Biotech, Ebersberg, Germany) was 48 bases long and complementary to bases coding for the 16 terminal amino acids of the glycoprotein sequence (Patchev et al., 1995). The VIP probe (MWGBiotech) was 30 bases long and complementary to the 10 terminal amino acids of the glycoprotein (Montagne et al., 1995). The probes were labeled by ${ }^{35} \mathrm{~S}$-dATP $(1200 \mathrm{Ci} / \mathrm{mmol}$; DuPont NEN, Bad Homburg, Germany) and terminal deoxynucleotidyl transferase. After hybridization, nonspecifically bound probe was removed by four washes of $15 \mathrm{~min}$ each in a solution of $50 \%$ formamide $/ 4 \times$ sodium chloride/sodium citrate buffer $(\mathrm{SCC}=0.15 \mathrm{M} \mathrm{NaCl}$ and $0.015 \mathrm{M}$ sodium citrate, $\mathrm{pH} 7.2)$ at $40^{\circ} \mathrm{C}$, followed by two rinses in $1 \times \mathrm{SSC}$ at room temperature. The slides were then dehydrated through graded ethanols containing $300 \mathrm{~mm}$ ammonium acetate and finally in absolute ethanol. The autoradiographic images of the hybridization signals were generated by apposition of the air-dried, slide-mounted sections to Hyperfilm $\beta$-max (Amersham International, Little Chalfont, UK) in standard x-ray cassettes for a period of $7 \mathrm{hr}$ for AVP and $7 \mathrm{~d}$ for VIP; radioactive standards were run alongside.

\section{Stereology}

Volume estimation. The volume of the SCN was estimated by using the principle of Cavalieri (1966). From each methacrylate-embedded hypothalamus, all sections containing the SCN were used (Fig. 1A). In each section, the cross-sectional area of the $\mathrm{SCN}$ was estimated by point counting (Gundersen et al., 1988; Madeira et al., 1995) at a final magnification of $331 \times$, using a grid of test points (Grid Stereological Package, Olympus Danmark A/S, Glostrup, Denmark) in which the interpoint distance was $31 \mathrm{~mm}$. The volume of the SCN was calculated from the total number of points that fell on the nucleus and the distance between the systematically sampled sections (Gundersen and Jensen, 1987; Madeira et al., 1995). Estimates were performed bilaterally, but because no right/left asymmetry was found, data were pooled from the two sides for each animal. The tissue shrinkage factor was not calculated, because it is generally accepted that tissue embedded in glycolmethacrylate undergoes virtually no shrinkage (Brængaard et al., 1990).

Estimation of the total number of neurons. Total neuronal numbers were estimated using the optical fractionator (West et al., 1991; Madeira et al., 1995). Microglia and oligodendrocytes, characterized by small and optically dense cell bodies, and astrocytes were not included in the estimates (Fig. $1 B$ ). To evaluate whether changes in the number of astrocytes, which are difficult to discriminate from neurons on the basis of cell size and shape at this level of resolution (van den Pol, 1980; Madeira et al., 1995), could interfere with the estimates of neuronal numbers, the total number of astrocytes was estimated separately in GFAP-immunostained material (Fig. 1C,D). For the estimation of the total number of SCN cells, all sections containing the SCN were used, which provided an average of 18 sections per nucleus. The fields of view were systematically sampled using a step size of $0.132 \mathrm{~mm}$ along the $x$ axis and $0.144 \mathrm{~mm}$ along the $y$ axis; the disector used had a counting frame area of $496 \mu \mathrm{m}^{2}$ at the tissue level and a fixed depth of $10 \mu \mathrm{m}$. Neurons were counted only when the nucleus was unambiguously apparent. An average of 130 neurons per nucleus were counted using the above-described sampling scheme, which can be summarized as follows. The section sampling fraction, ssf, was 1 , the area sampling fraction, asf, was 0.0261 , and the thickness sampling fraction, $t s f$, was 0.29 . The final magnification at the level of the monitor was $2800 \times$. Cell counting was carried out using an Olympus Video Stereological Analysis System (Olympus Danmark A/S, Glostrup, Den- 

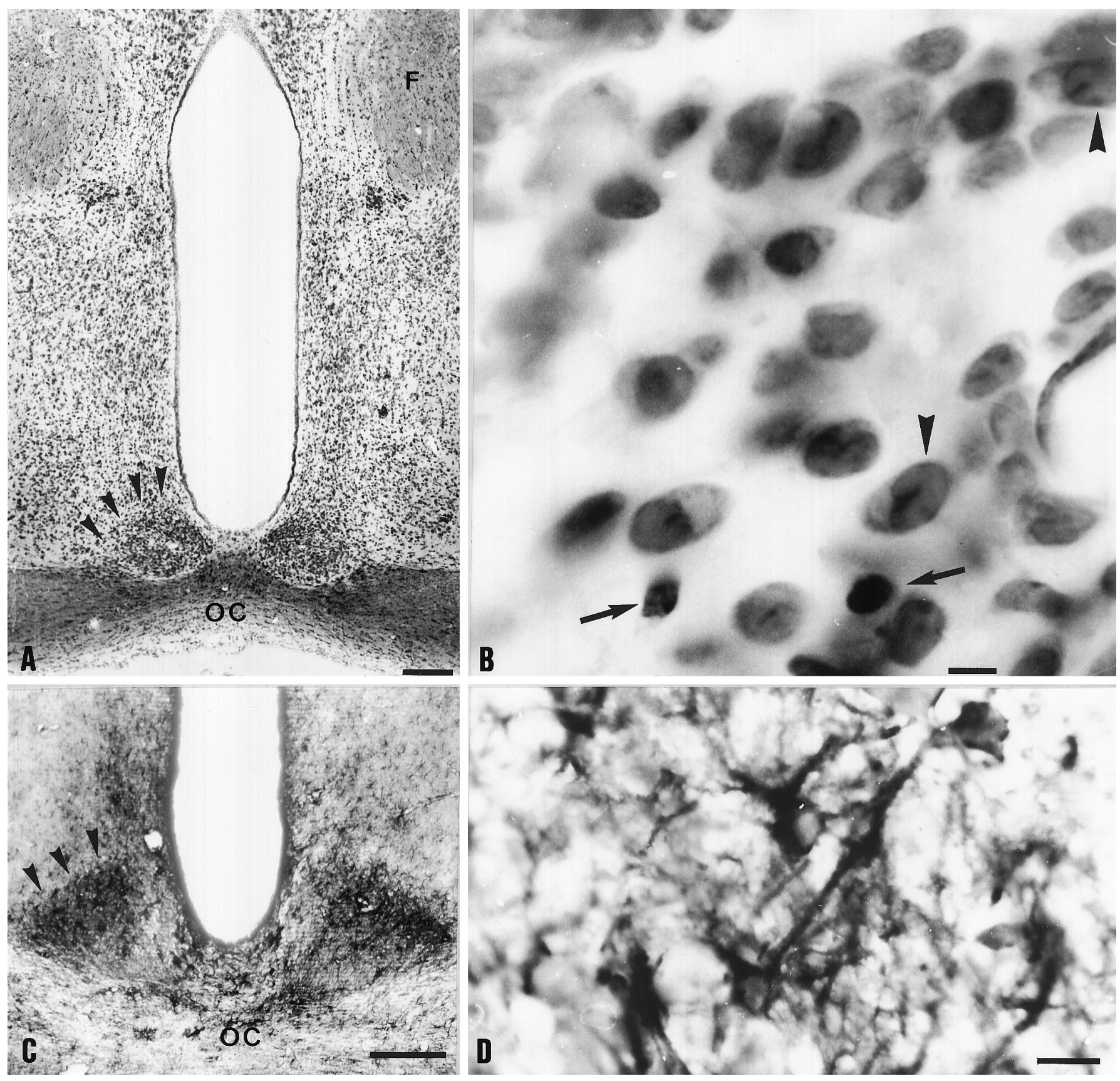

Figure 1. A, Photomicrograph of the SCN from a Giemsa-stained glycolmethacrylate-embedded coronal section of the hypothalamus. The dorsolateral boundary of the left SCN is indicated by arrowheads. Sections such as this were used to estimate the volume of, and the total number of neurons in, the SCN. OC, Optic chiasm; F, fornix. Scale bar, $200 \mu \mathrm{m}$. B, High-power micrograph of neurons and glial cells of Giemsa-stained SCN. Arrowheads indicate SCN neurons in which typical invaginations of the nuclear membrane can be visualized. Arrows indicate glial cells. Profiles such as these were not considered for the estimation of the total number of neurons. Scale bar, $5 \mu \mathrm{m}$. $C$, Photomicrograph of a GFAP-immunostained section, counterstained with cresyl violet, through the mid-SCN. The arrowheads indicate the dorsolateral boundary of the nucleus. Note the strong GFAP-immunoreactivity displayed by the SCN relative to the adjacent hypothalamus. Scale bar, $50 \mu \mathrm{m}$. $D$, High magnification of GFAP-immunostained glial cells. Only structures with morphological features and staining properties similar to these were considered for counting purposes. Scale bar, $10 \mu \mathrm{m}$.

mark) and a Heidenhain MT-12 microcator (Heidenhain GmbH). Because there were no right/left asymmetries in the volume of the SCN, the right and left hemispheres were sampled alternately for this estimation.

By applying the same stereological technique, the total number of SCN astrocytes and the total numbers of AVP-, VIP-, GRP-, and SSimmunoreactive neurons were estimated independently from appropriately immunostained sections. The sampling schemes used were as described above, with the following modifications. (1) Alternate sections were used, which provided an average of 12 sections per nucleus; consequently, the $s s f$ was 0.5 ; (2) microscope fields were sampled using an interframe distance of $0.048 \mathrm{~mm}$ ( $x$-axis) by $0.046 \mathrm{~mm}$ ( $y$-axis); the area of the counting frame used for astrocytes and for AVP- and VIPimmunoreactive neurons was $840 \mu \mathrm{m}^{2}$, and hence the asf was 0.3804 ; for GRP- and SS-immunoreactive neurons, the area of the counting frame was $1036 \mu \mathrm{m}^{2}$ and thus the asf was 0.4692 ; (3) the disector had a fixed depth of $8 \mu \mathrm{m}$, and the $t s f$ was 0.4 ; and (4) the final magnification at the level of the monitor was $3340 \times$. With use of these sampling schemes, an average of 110 astrocytes, 100 AVP-immunoreactive cells, 70 VIPimmunoreactive cells, 50 GRP-immunoreactive cells, and 20 SSimmunoreactive cells were counted per nucleus. Cell counts were per- 
formed on both sides of the brain, and the data were pooled for each animal. Cytoplasmic GFAP immunoreactivity was the criterion for astrocyte identification (Fig. 1D), and immunostaining of the perikaryal cytoplasm with a relatively unstained nucleus was the criterion for the identification of AVP-, VIP-, GRP-, and SS-containing neurons.

\section{Semiquantitative analysis of autoradiograms}

Autoradiographic signals from the SCN were digitized with a video densitometer (Cybertech CS-1, Image Documentation System, Berlin, Germany) and processed using the Cybertech Image Processing System (Version 1.2, 1990). Unidimensional densitometry was used to integrate and compare the optical densities of hybridization signals and for correction of the background. The quantifications were made on both sides of the 12-20 autoradiographic images of the SCN obtained per animal. The same hardware and software adjustments were applied in the control and experimental animals. The values were expressed in arbitrary optical density units.

\section{Statistical analysis}

A two-way ANOVA was performed on data from control and experimental groups analyzed after 6 and 12 months of treatment to discern the main effects. Age and treatment were used as independent variables. A two-way ANOVA was also applied to evaluate the effects of treatment and time of day on serum corticosterone concentrations. To test for the effect of treatment on the morphometric data obtained from immunostained material and for the effect of time of day on blood alcohol concentrations, a one-way ANOVA was performed. Animals were used as replicates and the remainder mean square as the error term. Subsequent multiple comparisons were performed using post hoc linear polynomial contrasts. Throughout the text, data are presented as means with their coefficients of variation $(\mathrm{CV}=\mathrm{SD} / \mathrm{mean})$. Differences were considered to be significant if $p<0.05$. The coefficient of error (CE) of the individual estimates was calculated as shown by West et al. (1991).

\section{RESULTS}

\section{Body and brain weights}

The mean body and brain weights are presented in Table 1. ANOVA showed that the variations in the body weights were dependent on the effect of treatment $\left(F_{(2,64)}=21.78 ; p<5 \times\right.$ $\left.10^{-4}\right)$. Eight- and 14-month-old control rats were significantly heavier than the age-matched pair-fed control and ethanoltreated rats. No difference was found between the mean body weights of pair-fed controls and ethanol-treated rats. In addition, withdrawn rats weighed less than control rats, but they were heavier than the age-matched ethanol-treated and pair-fed control rats. The animals from the 14-month-old groups were globally

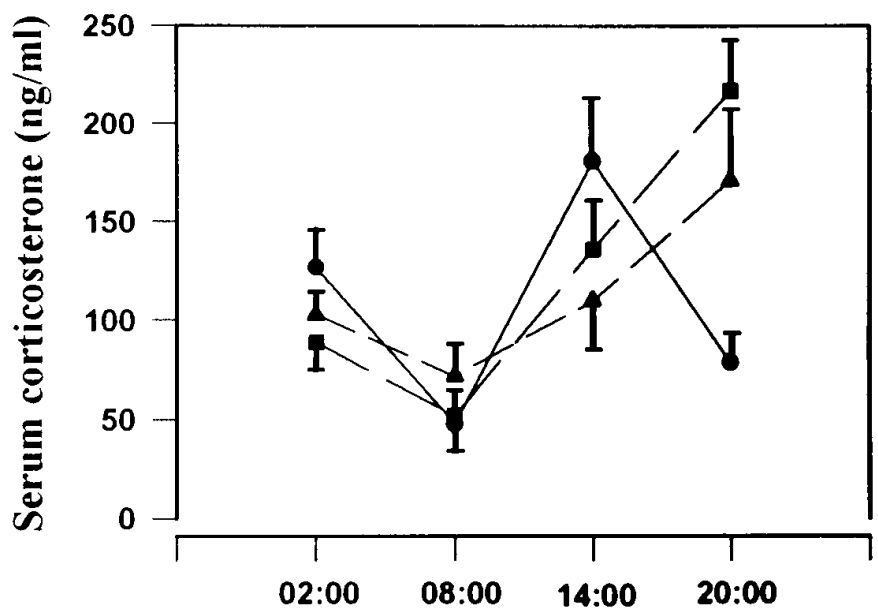

Figure 2. Diurnal variation of serum corticosterone concentrations in control $(\square-\mathbf{\square} ; n=6$ ), ethanol-treated $(\mathbf{-} ; n=7)$, and withdrawn $(\boldsymbol{\Lambda}-\mathbf{\Lambda} ; n=7)$ rats. Symbols represent means, and error bars represent SEM. Abscissa: time of experiment. For further details, see Results.
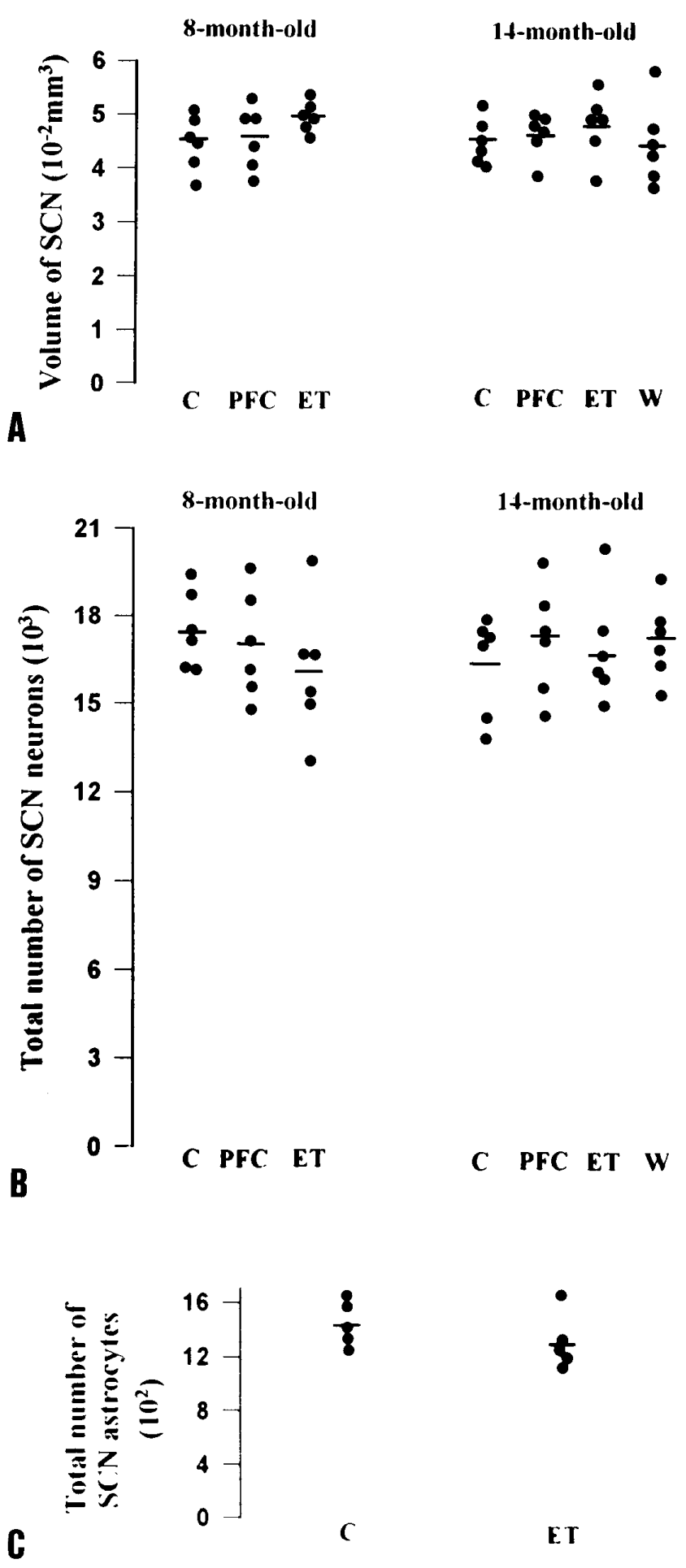

Figure 3. Graphic representation of the morphometric data obtained from the SCN of control $(C)$, pair-fed control $(P F C)$, ethanol-treated $(E T)$, and withdrawn $(W)$ rats after experimental periods of 6 months (8-month-old animals) and 12 months (14-month-old animals). $A$, Volume of the SCN. $B$, Total number of SCN neurons. $C$, Total number of astrocytes in the SCN of 14-month-old rats. Horizontal bars represent mean values.

heavier than those from the 8-month-old groups, but no significant effect of age was found $\left(F_{(1,64)}=3.42 ; p=0.069\right)$; likewise, no interaction between age and treatment was detected $\left(F_{(2,64)}=\right.$ $1.35 ; p=0.267)$. No effects of age $\left(F_{(1,64)}=3.50 ; p=0.066\right)$ and 
treatment $\left(F_{(2,64)}=1.86 ; p=0.164\right)$ on brain weights were found (Table 1).

\section{Blood ethanol concentrations}

The mean amount of ethanol consumed, calculated from all ethanol-treated rats used in this study, was $9.0 \mathrm{gm} / \mathrm{kg}$ body weight per day. Blood ethanol concentrations were lower in the evening than in the morning $\left(F_{(1,44)}=285.66 ; p<5 \times 10^{-4}\right)$, a finding that is compatible with the observation that alcohol-treated rats consume the available food at a constant rate during the dark phase and almost ignore it during the light phase (Miller, 1992). The values found ranged between $117(0.04)$ and $91(0.06) \mathrm{mg} / \mathrm{dl}$ for the samples collected in the morning and in the evening, respectively.

\section{Corticosterone concentrations}

In control animals, the serum corticosterone levels were lowest at the beginning of the light phase and reached their highest values at 8:00 P.M. (Fig. 2). In ethanol-treated rats, the highest concentration was reached earlier, i.e., at 2:00 P.M., and the magnitude of the diurnal variations was smaller than in controls (Fig. 2). Although exposure to ethanol, either acutely (Ellis, 1966) or over a short period (Tabakoff et al., 1978), has been reported to increase the plasma levels of corticosterone, there is increasing evidence that long-term exposure to ethanol might lead to an adaptation of the hypothalamic-pituitary-adrenal axis (Spencer and McEwen, 1990; Rivier, 1996). Our data are consistent with this view, because we found that in rats consuming ethanol for 12 months, the mean serum corticosterone levels do not differ from those of controls. Furthermore, no differences were found between the corticosterone concentrations of these groups and those of rats withdrawn from alcohol for a period of 6 months. In addition to showing that treatments had no effects on serum corticosterone concentrations $\left(F_{(2,67)}=0.30\right.$; $\left.p=0.740\right)$, however, ANOVA revealed significant fluctuations in corticosterone secretion, which were related to the time of day $\left(F_{(3,67)}=19.10\right.$; $\left.p<5 \times 10^{-4}\right)$ and a significant interaction between treatment and the diurnal variations in corticosterone concentrations $\left(F_{(6,67)}=\right.$ 2.29; $p=0.044)$.

\section{Volume of SCN}

No significant effects of treatment $\left(F_{(2,30)}=1.99 ; p=0.153\right)$ and age $\left(F_{(1,30)}=0.01 ; p=0.994\right)$ on the volume of the SCN were found (Fig. $3 A$ ), and there were no variations in the volume of the SCN between ordinary controls and pair-fed controls. In the experimental groups, the volumes of the SCN displayed a higher mean relative variation among animals $(\mathrm{CV}=0.12)$ than in the control groups $(\mathrm{CV}=0.10)$; the mean $\mathrm{CE}$ of the estimates was 0.025 .

\section{Total number of neurons}

The estimated numbers of neurons in the SCN of control, pair-fed control, ethanol-treated, and withdrawn rats at the different ages analyzed are shown in Figure $3 B$. No effects of treatment $\left(F_{(2,30)}\right.$ $=0.31 ; p=0.737)$ or age $\left(F_{(1,30)}=0.01 ; p=0.920\right)$ on the total number of neurons were found. The mean $\mathrm{CV}$ of the neuronal numbers was 0.11 in control rats, 0.13 in ethanol-treated rats, and 0.08 in withdrawn rats; the average CE of the estimates was 0.079 .

\section{Total number and relative proportion of astrocytes}

The total numbers of astrocytes estimated on the basis of counts of GFAP-positive cells in 14-month-old control and ethanoltreated rats are shown in Figure $3 C$. The mean number of astro- cytes did not vary between control and ethanol-treated rats $\left(F_{(1,8)}\right.$ $=1.48 ; p=0.258)$, and no qualitative differences were observed in the morphology of the astrocytes between these groups. The mean observed relative variation among animals was higher in the ethanol-treated group $(\mathrm{CV}=0.16)$ than in the control group $(\mathrm{CV}=0.12)$; the mean $\mathrm{CE}$ of the estimates was 0.057. Astrocytes identified by immunostaining with antibody against GFAP (Bignami and Dahl, 1977; Morin et al., 1989) were estimated to amount to $\sim 10 \%$ of the number of neurons in the SCN, confirming previous estimates from our laboratory (Madeira et al., 1995). Other estimates based on quantitative ultrastructural observations have suggested that the proportion of astrocytes is much higher, amounting to $30 \%$ (Güldner, 1983) or $65 \%$ (van den Pol et al., 1992) of the number of neurons.

\section{AVP-immunoreactive neurons}

These neurons were concentrated in the dorsomedial division of the SCN (Fig. 4), along its entire rostrocaudal extent, and most of them had fusiform cell bodies with beaded neurites extending from the poles of the cell bodies (Fig. $4 G, H$ ). In addition, the plexus formed by AVP fibers was also much denser in the dorsomedial division of the SCN than in the adjacent ventrolateral division, where fibers were sparse (Fig. $4 A-B$ ). These findings are compatible with previous observations made in the hamster (Card and Moore, 1984) and in the rat (van den Pol and Tsujimoto, 1985). The distribution of AVP-immunoreactive neurons and fibers was identical in control, ethanol-treated, and withdrawn rats, but the cell density and the staining intensity of the fibers within the nucleus and in its projection to the subparaventricular zone appeared to be reduced in ethanol-treated and withdrawn rats (Fig. $4 C-F$ ). The total number of AVP neurons in control rats is 1773 (Fig. $4 I$ ). They therefore represent $\sim 10 \%$ of the total neuronal population of $\sim 17,000$, a smaller percentage than that reported by Sofroniew and Weindl (1980), who found that AVP neurons numbered 2055 in adult rats of a nonspecified strain and accounted for $17 \%$ of all neurons. In other studies, the number of AVP neurons has been estimated as 1137 (Brown Norway rats; Roozendaal et al., 1987), 3176 (colchicine-treated Sprague Dawley rats; Moore and Speh, 1993), and 1580 (Wistar rats; Swaab et al., 1995).

ANOVA showed that the variations in the total number of AVP-immunoreactive neurons were dependent on the effect of treatment $\left(F_{(2,15)}=30.72 ; p<5 \times 10^{-4}\right)$. When compared with controls, the number of AVP neurons was reduced by $33 \%$ in ethanol-treated rats and $39 \%$ in withdrawn rats; however, no significant difference was found between ethanol-treated and withdrawn rats (Fig. 4I). The inter-animal CV was higher in the experimental groups $(\mathrm{CV}=0.13)$ than in controls $(\mathrm{CV}=0.09)$; the mean $\mathrm{CE}$ of the estimates was 0.042 .

\section{VIP-immunoreactive neurons}

VIP derives from a precursor molecule, prepro-VIP, which after cleavage also yields peptide histidine isoleucine and peptide histidine valine (Nishizawa et al., 1987). Yet, VIP is present at a higher concentration than these other peptides (Mikkelsen and Fahrenkrug, 1994), and we therefore focused our analyses on VIP-immunoreactive neurons (Fig. 5). These cells display a round or elongate shape and give rise to one or two unbeaded processes (Fig. $5 G$ ); they occupy the ventrolateral division of the SCN, and the most ventrally located were frequently found to extend into the optic chiasm (Fig. 5A). However, VIP-immunoreactive cell bodies were not detected in the rostral and caudal extremities of 

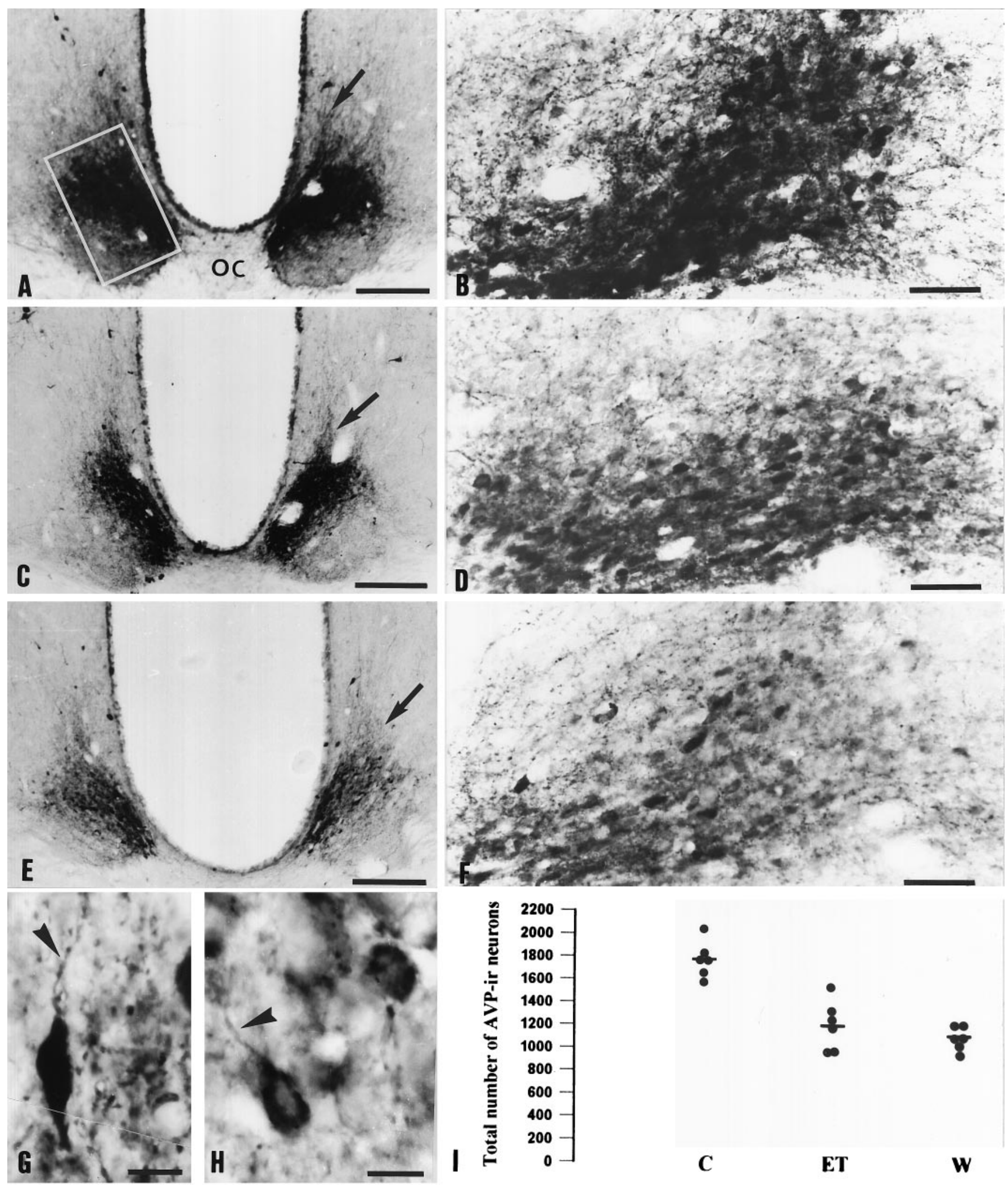

Figure 4. AVP immunoreactivity in the $\mathrm{SCN}$ of control $(A, B)$, ethanol-treated $(C, D)$, and withdrawn $(E, F)$ rats. $A, C, E$, Photomicrographs of coronal sections at mid-SCN levels. The box in $A$ delineates the area shown at higher magnification in $B$. The corresponding areas in $C$ and $E$ are shown at higher magnification in $D$ and $F$, respectively. Densely stained AVP-immunoreactive neurons concentrated in the dorsomedial part of the nucleus project fibers dorsally (arrows) along the wall of the third ventricle. Note that the density of this projection is reduced in the ethanol-treated rat and in the withdrawn rat. $O C$, Optic chiasm. Scale bars, $200 \mu \mathrm{m} . B, D, F$, Enlargements of the boxed area in $A$ and corresponding areas in $C$ and $E$. The fields illustrated have been rotated so that the dorsolateral part of the delineated areas appears to the right of the micrographs in $B, D$, and $F$. The concentration of AVP-immunoreactive neurons and the density of the plexus of fibers is higher in the control rat $(B)$ than in the ethanol-treated (Figure legend continues) 
the nucleus. The density of VIP-immunoreactive fibers was high in both divisions of the SCN (Fig. 5A,B), and fibers could be visualized throughout the entire extent of the nucleus. The distribution of cells and fibers was similar in all groups analyzed, and these observations are in keeping with previous studies in the hamster (Card and Moore, 1984), mouse (Mikkelsen and Fahrenkrug, 1994), and rat (van den Pol and Tsujimoto, 1985). However, the staining intensity of the fiber plexus within the SCN and in the projection coursing to the subparaventricular zone along the wall of the third ventricle appeared to be lighter in ethanoltreated and withdrawn rats than in controls (Fig. $5 A-F$ ). The total number of VIP neurons in control SCN was 1180 (Fig. 5H), representing $\sim 7 \%$ of the total number of SCN neurons. In previous studies, using different morphometric methods, Chee et al. (1988) found 1152-1657 VIP neurons in Brown Norway rats, and Moore and Speh (1993) found 2081 such neurons in colchicinetreated Sprague Dawley rats, which they estimated as representing $20-26 \%$ of the total number of neurons.

ANOVA revealed that treatment had a significant effect on the total number of VIP-immunoreactive neurons $\left(F_{(2,15)}=80.36\right.$; $\left.p<5 \times 10^{-4}\right)$. The mean number of VIP neurons was reduced by $34 \%$ in ethanol-treated rats; in addition, a further decrease of $47 \%$ in the mean number of VIP neurons was found in withdrawn rats relative to ethanol-treated rats (Fig. $5 H$ ). Again, the interindividual variation of this estimate was greater in experimental groups $(\mathrm{CV}=0.20)$ than in controls $(\mathrm{CV}=0.07)$; the mean $\mathrm{CE}$ of the estimates was 0.069 .

\section{GRP-immunoreactive neurons}

Although GRP is possibly colocalized with VIP (Okamura et al., 1986), there is evidence that these peptides are produced by different sets of neurons of the ventrolateral division of the SCN (van den Pol and Tsujimoto, 1985). It is known, furthermore, that in these neurons the expression of circadian rhythms is modulated by photic stimulation (Shinohara et al., 1993); however, whereas VIP-immunoreactive neurons are activated during the dark phase, GRP-immunoreactive neurons are activated during the light phase (Shinohara et al., 1993). Because the processing of light information is basically different in these two subpopulations, we incorporated a separate analysis of GRP-synthesizing neurons in this study (Fig. 6). GRP-containing cell bodies are present throughout the SCN, with the exception of the most caudal and the most rostral extremities of the nucleus, where only immunoreactive fibers can be seen. Most of the GRP neurons are bipolar in form, with ovoid cell bodies giving rise to a single beaded process from each pole (Fig. $6 G, H$ ). In confirmation of previous observations of van den Pol and Tsujimoto (1985) and Mikkelsen et al. (1991), in the rostral portion of the SCN the GRP neurons are confined to the ventral part of the nucleus, often abutting or protruding into the optic chiasm, whereas more caudally, the cells are scattered throughout the entire ventrolateral subdivision (Fig. $6 A$ ). The distribution of GRP neurons and fibers was similar in control and experimental groups, but the staining intensity appeared to be reduced in ethanol-treated and withdrawn rats (Fig. 6A-F).
Estimates of the total number of GRP-immunoreactive neurons are shown in Figure $6 I$; such neurons represent $\sim 4 \%$ of the total neuronal population in the SCN. A significant effect of treatment on the total number of neurons was found $\left(F_{(2,13)}=16.58 ; p=\right.$ $\left.3 \times 10^{-4}\right)$. The mean total number of neurons was $32 \%$ smaller in ethanol-treated than in control rats and $26 \%$ smaller in withdrawn than in ethanol-treated rats (Fig. 6I). The interindividual variation in the number of neurons was smaller in the experimental groups $(\mathrm{CV}=0.13)$ than in controls $(\mathrm{CV}=0.20)$; the mean $\mathrm{CE}$ of the estimates was 0.072 .

\section{SS-immunoreactive neurons}

Neurons containing SS are believed to participate only in local circuits within the SCN, modulating the activity of the AVP- and VIP-containing neurons (Daikoku et al., 1992; Fukuhara et al., 1994). The perikarya of SS-immunoreactive neurons were distributed throughout the rostrocaudal extent of the SCN but confined to its dorsomedial division (Fig. $7 A, B$ ), and they displayed an ovoid or spherical shape (Fig. $7 G, H$ ). SS-immunoreactive fibers were present in the ventrolateral and dorsomedial divisions of the SCN but did not extend outside its boundaries, a finding that is in agreement with previous observations (Card and Moore, 1984; van den Pol and Tsujimoto, 1985). The pattern of cell and fiber distribution was similar in all groups analyzed, but the staining intensity of SS-immunoreactive fibers and the cell density were apparently decreased in ethanol-treated and withdrawn rats (Fig. $7 A-F)$. Our results show that among the specific subpopulations of $\mathrm{SCN}$ neurons, SS-immunoreactive neurons are the least numerous, representing only $1 \%$ of the total neuronal population in the $\mathrm{SCN}$. Treatment had a significant effect on the total number of SS-immunoreactive neurons $\left(F_{(2,13)}=7.17 ; p=0.008\right)$. The mean number of neurons was $20 \%$ smaller in ethanol-treated than in control rats, and $12 \%$ less in withdrawn than in ethanol-treated rats (Fig. 7I). The mean CV was 0.08 in the control and 0.21 in the experimental groups; the mean CE of the estimates was 0.078 .

\section{Neuropeptide mRNA expression}

From the SCN subpopulations investigated, AVP- and VIPproducing neurons were found to be the most abundant in the dorsomedial and ventrolateral subdivisions of the SCN, respectively. There is evidence, furthermore, that the circadian rhythm of AVP mRNA expression is endogenously driven, whereas that of VIP mRNA expression is entrained by photic stimuli (Uhl and Reppert, 1986; Duncan et al., 1995). We therefore tested whether AVP and VIP mRNA expression was altered by CET and, if so, whether withdrawal from alcohol could reverse the alcoholinduced alterations in peptide mRNA expression. As reported previously (Card et al., 1988), AVP mRNA labeling was present in the dorsomedial region of the SCN (Fig. $8 A-C$ ), whereas VIP mRNA was detected in the ventrolateral region of the nucleus (Fig. $8 E-G$ ). In control rats, there was a high expression of both peptide mRNAs. Conversely, in ethanol-treated and withdrawn rats, the hybridization signals were reduced dramatically for both peptides. Comparisons of the steady-state AVP and VIP mRNA signals between ethanol-treated and withdrawn rats revealed that

\section{$\leftarrow$}

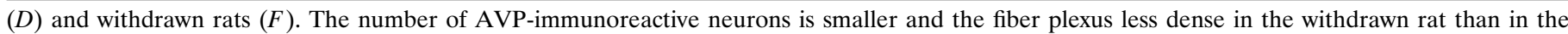

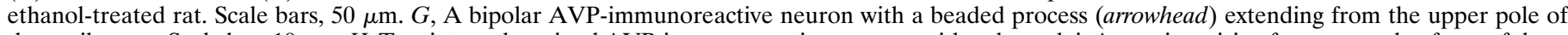



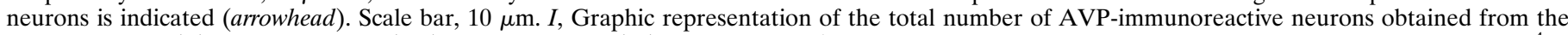

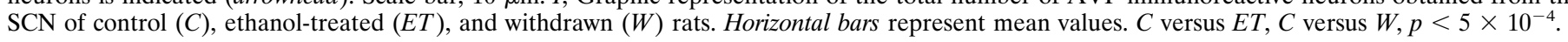



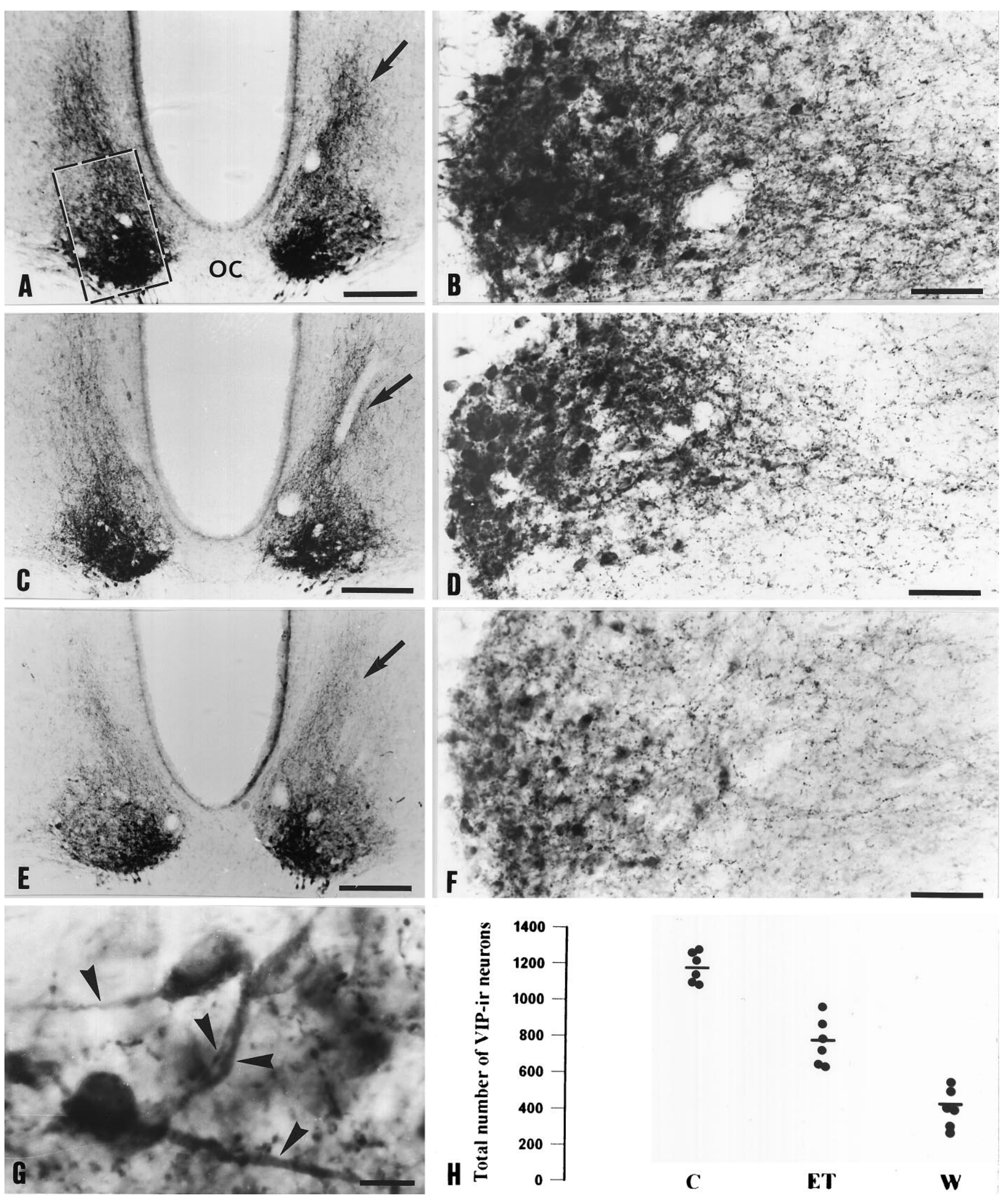

Figure 5. VIP immunoreactivity in the $\mathrm{SCN}$ of control $(A, B)$, ethanol-treated $(C, D)$, and withdrawn $(E, F)$ rats. $A, C, E$, Photomicrographs of coronal sections through mid-SCN levels. The box in $A$ delineates the area shown at higher magnification in $B$. The corresponding areas in $C$ and $E$ are shown at higher magnification in $D$ and $F$, respectively. VIP-immunoreactive neurons are confined to the ventrolateral part of the nucleus, and some are embedded in the optic chiasm $(O C)$. A dense projection of VIP-immunoreactive fibers (arrows) courses dorsally along the wall of the third ventricle. The density of this projection is markedly reduced in the ethanol-treated rat $(C)$ and still more in the withdrawn rat $(E)$. Scale bars, $200 \mu \mathrm{m}$. $B, D, F$, Enlargements of the boxed area in $A$ and corresponding areas in $C$ and $E$. The fields illustrated have been rotated, (Figure legend continues) 
the signals were much weaker in the withdrawn than in the ethanol-treated group (Fig. 8). Thus, steady-state in situ hybridization measurements of the mRNAs encoding AVP and VIP strongly support the progressive reductions in AVP and VIP immunoreactivity observed during CET and alcohol withdrawal.

\section{DISCUSSION}

Most of the investigations of structural alterations associated with CET have been centered on the hippocampal formation and cerebellar cortex because of the involvement of these regions of the brain in cognitive functions and motor coordination, both of which are markedly affected by CET (for reviews, see Walker et al., 1981; Charness, 1993). Such studies have shown that the morphological alterations induced by CET are primarily degenerative in nature and consist of reductions in the numbers of neurons and synapses, changes in the size of neuronal cell bodies and synaptic contacts, loss of dendritic branches and spines, and disruption of cell organelles (Walker et al., 1981; Tavares et al., 1983, 1987; McMullen et al., 1984; Paula-Barbosa and Tavares, 1985; Paula-Barbosa et al., 1986, 1993; Pentney and Quigley, 1987; Cadete-Leite et al., 1989; Bonthius and West, 1990, 1991).

Because neuroendocrine abnormalities are frequently associated with chronic alcohol exposure, the hypothalamus has long been considered a probable target for alcohol; however, approaches to the study of the effects of alcohol on the hypothalamus have so far been mostly functional and have permitted very little insight into the question of whether these disorders depend on changes in hypothalamic structure. As far as we are aware, the only morphological studies that address the effects of alcohol on hypothalamic nuclei are our own studies of the supraoptic nucleus of adult rats exposed to alcohol during periods of 12 and 18 months (Madeira et al., 1993; Ruela et al., 1994); in these studies we showed that CET leads to the loss of $40 \%$ of the neurons of the supraoptic nucleus and, paradoxically, to a marked enlargement of the nucleus as a whole, as a result of the increase in the volume of the surviving neurons and of the associated neuropil. We suggested that the enlargement of the remaining neurons and of the nucleus as a whole represented compensatory hypertrophy induced by the neuronal loss.

In this study we present evidence that CET, despite the marked alterations it induces in functions modulated by the SCN, does not cause major anatomical changes in this nucleus. Specifically, we found that the total number of neurons and the volume of the SCN are identical in control and ethanol-treated rats, regardless of the duration of alcohol consumption. It could be argued that the absence of change in total cell numbers might be the net result of a decrease in the number of neurons and a parallel increase in the number of astrocytes, but our results allow us to eliminate this possibility because the total number of GFAP-immunoreactive cells is identical in control and ethanol-treated rats. Likewise, the components of the neuropil, predominantly the neurites of SCN cells, are probably not altered significantly by CET, as can be inferred from the absence of variations in total cell numbers and from the unchanging volume of the SCN between control and ethanol-treated rats.

We can therefore conclude that the neurotoxic effects of alcohol are not uniform throughout the hypothalamus, because in contrast to the magnocellular neurons of the supraoptic nucleus (Madeira et al., 1993), the parvocellular neurons of the SCN are remarkably resistant to its effects. This finding was not entirely unexpected, because there is compelling evidence that excitotoxicity, which is the most probable mechanism underlying alcoholinduced neurodegeneration (Lovinger, 1993), was not observed in the SCN after exposure to kainic acid (Peterson and Moore, 1980) or high concentrations of glutamate (Meijer et al., 1993; Ding et al., 1994). Nonetheless, excitotoxic mechanisms might be involved in responses to CET in the retinorecipient area of the SCN because of evidence that (1) in CET there is both decreased activation of $\mathrm{GABA}_{\mathrm{A}}$ receptors and enhanced glutamatergic activity (attributable to upregulation of NMDA receptors) (for reviews, see Hunt, 1993; Lovinger, 1993; Korpi, 1994) and (2) the excitation evoked in SCN cells by glutamate, almost certainly the primary neurotransmitter of the retinohypothalamic tract (van den Pol and Dudek, 1993; Morin, 1994), is mediated by the same subtype of glutamate receptor (Mikkelsen et al., 1993; Gannon and Rea, 1994), although AMPA and metabotropic receptors might also be involved (Mick et al., 1995).

Several factors might have accounted for the absence of CETinduced NMDA-mediated toxicity. First, there is increasing evidence that the sensitivity of neuronal populations to alcohol depends on the receptor specificity of the cells, and SCN neurons express the NR1 and NR2C subunits of NMDA receptors (Mikkelsen et al., 1993; Gannon and Rea, 1994) but not the subunits modified by CET, i.e., the NR2A and NR2B subunits (Hu et al., 1996). With respect to $\mathrm{GABA}_{\mathrm{A}}$ receptors, they contain the $\alpha_{2}, \alpha_{3}, \alpha_{5}$, and $\gamma_{2}$ subunits (Gao et al., 1995), and the available data indicate that CET decreases the levels of the $\alpha_{2}$ and $\alpha_{5}$ subunits but does not alter the expression of the $\alpha_{3}$ subunit (Korpi, 1994), the most abundant in the SCN neuropil (Gao et al., 1995), where most of the GABAergic synapses are established (Decavel and van den Pol, 1990). In addition, SCN cells contain high levels of the GluR2 subunit of the AMPA receptor (Gannon and Rea, 1994), which might provide additional protection against CET-induced NMDA-mediated toxicity, because there is evidence that in heteromeric AMPA receptors the $\mathrm{Ca}^{2+}$ impermeability of GluR2 is dominant (Jonas et al., 1994). Second, several lines of evidence indicate that serotonin, an abundant neurotransmitter in the retinorecipient area of the SCN produced by neurons of the raphe nuclei (van den Pol and Tsujimoto, 1985; Morin, 1994), modulates retinohypothalamic-mediated glutamatergic neurotransmission by lowering the extracellular concentration of glutamate (Selim et al., 1993; Srkalovic et al., 1994). CET enhances serotonin release in several regions of the brain (Hunt, 1993), and should this phenomenon occur in the SCN, the availability of glutamate might be decreased by CET. Third, our results

$\leftarrow$

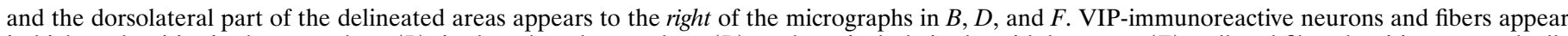

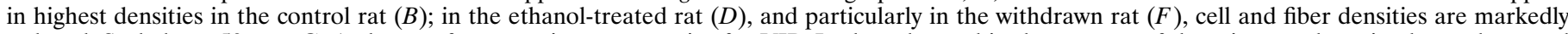

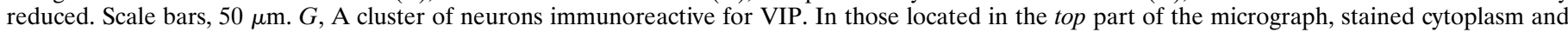

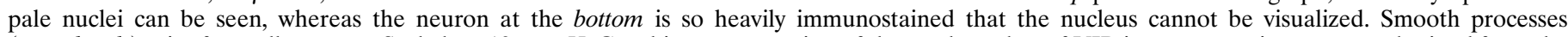



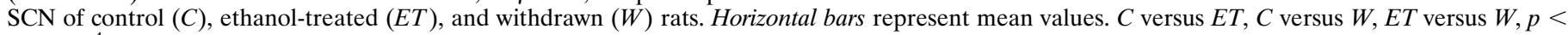
$5 \times 10^{-4}$. 



Figure 6. GRP immunoreactivity in the SCN of control $(A, B)$, ethanol-treated $(C, D)$, and withdrawn $(E, F)$ rats. $A, C, E$, Photomicrographs of coronal sections through mid-SCN levels. The box in $A$ delineates the area shown at higher magnification in $B$. The corresponding areas in $C$ and $E$ are shown at higher magnification in $D$ and $F$, respectively. GRP-immunoreactive cell bodies are concentrated in the ventrolateral part of the nucleus, and some are embedded in the optic chiasm (OC). GRP-immunoreactive fibers (arrows) course dorsally, adjacent to the third ventricle wall. Scale bars, $200 \mu \mathrm{m}$. $B, D$, $F$, Enlargements of the boxed area in $A$ and corresponding areas in $C$ and $E$. The fields illustrated have been rotated so that the dorsolateral part of the delineated areas appears to the right of the micrographs in $B, D$, and $F$. In the control rat $(B)$, a high concentration of (Figure legend continues) 
show that CET does not alter the total number of astrocytes nor the normal astrocyte-to-neuron ratio. This fact is of the utmost importance for the protection of the SCN against the toxic effects of ethanol, because there is evidence that SCN astrocytes can modulate extracellular ion levels in response to glutamate and serotonin (van den Pol et al., 1992). Finally, SCN neurons express high levels of nerve growth factor (NGF) receptor immunoreactivity (Kiss et al., 1993) and contain both NGF and its precursor (Senut et al., 1990; Bina and Rusak, 1991). That the presence of neurotrophic factors might counteract the toxic effects of ethanol is suggested by in vivo (Walker et al., 1993) and in vitro studies (Heaton et al., 1993), which show that NGF reduces the toxic effects of ethanol and protects neurons from glutamate-induced excitotoxicity.

Given that neuronal numbers in SCN do not fall as a consequence of CET, we considered the possibility that changes in the peptide expression of SCN neurons might provide an explanation for the alcohol-induced disruption of circadian rhythms. Our findings indicate a substantial CET-induced loss in the numbers of neurons producing AVP, VIP, GRP, and SS. A possible explanation for the reductions in these neuronal populations is cell death, a hypothesis that our data do not corroborate because they establish that there is no reduction in total neuronal number in the SCN as a result of CET. It should be said, however, that our estimates of total neuron numbers in ethanol-treated rats cannot completely negate such a possibility. Because of the large variation in neuron numbers among ethanol-treated rats $(13 \%)$, we theoretically may have failed to detect small losses in the subpopulations of the SCN amounting to an overall loss of $7.6 \%$ of the total number of neurons. However, AVP-, VIP-, GRP-, and SS-immunoreactive neurons together represent only $22 \%$ of the total neuronal population of the $\mathrm{SCN}$, and there is no reason to assume that the remaining neurons (78\% of the total neurons) would not also be vulnerable to the effects of chronic alcohol exposure. In fact, studies performed in other regions of the brain (Lescaudron et al., 1986) have shown that GABA neurons, which represent the most abundant subpopulation in the SCN and are equally distributed in the dorsomedial and ventrolateral divisions of the nucleus (Moore and Speh, 1993), are also markedly vulnerable to the toxic effects of ethanol. Furthermore, the finding that in withdrawn rats the overall loss of AVP-, VIP-, GRP-, and SS-immunoreactive neurons is $9 \%$ of the total neurons and that the observed interindividual variance in the estimations of total neuron numbers is smaller $(8 \%)$ and no cell loss was observed, allows us to conclude that cell death is definitely not the major underlying factor of the reductions observed in the subpopulations analyzed. Therefore, they must depend on decreased synthesis of the identifying peptides or on increased axonal transport and/or release of the peptides. The latter possibilities are unlikely because CET has been shown in previous studies to result in reduced rates of fast axonal transport in (McLane, 1987) and of neuropeptide release from these cells (Wang et al., 1991) and in disruption and loss of microtubules (Paula-Barbosa and Tavares, 1985), on which rapid axon transport depends. We therefore favor the possibility that the reduction in the number of neuropeptidecontaining neurons is a consequence of reduced synthesis, and this interpretation is strengthened by our observation that mRNAs for two of these peptides, AVP and VIP, appear to be downregulated in CET (weaker hybridization signals).

Several mechanisms can be involved to explain CET-induced depression of neuropeptide synthesis. First, ethanol-treated rats have high levels of circulating corticosterone and low levels of circulating testosterone (Ellis, 1966; Tabakoff et al., 1978; Cicero et al., 1979), and there is evidence that glucocorticoids influence AVP synthesis (Davis et al., 1986) and gonadal steroids modulate the expression of AVP, VIP, and SS (for review, see Madeira and Lieberman, 1995). The alterations we found, however, are not likely to be causally related to these hormonal effects, because glucocorticoids do not interfere with AVP synthesis in the SCN (Davis et al., 1986) and SCN neurons do not contain glucocorticoid receptors (Cintra et al., 1994) or receptors for gonadal steroids (Simerly et al., 1990; Zhou et al., 1994). Second, CET affects virtually all known neurotransmitter systems in the brain (Shanley and Wilce, 1993; De Witte, 1996) and might therefore lead to changes in the interactions between SCN neurons and their afferents. This hypothesis is suggested by the observation that selective deafferentation of the $\mathrm{SCN}$, either by loss of retinohypothalamic fibers (Laemle, 1992) or destruction of its serotoninergic input (Kawakami et al., 1994), leads to significant reductions in the number of VIP-immunoreactive neurons, the main targets of these afferents (Morin, 1994). The reduction in the number of VIP-immunoreactive neurons detected in our study suggests that CET might alter the balance between the excitatory and the inhibitory inputs to the retinorecipient area of the SCN and favor the latter. The fact that availability of presynaptic GABA, the most abundant neurotransmitter in the SCN (Decavel and van den Pol, 1990; Moore and Speh, 1993; Morin, 1994; Buijs et al., 1995), is not altered by CET (Frye and Fincher, 1988; Tremwel et al., 1994) lends support to this possibility. The finding of a similar reduction in the total number of neurons of every subpopulation analyzed does not negate this possibility, because the complex intrinsic connectivity of the SCN (Daikoku et al., 1992; van den Pol and Dudek, 1993) implies that changes in neurons of the retinorecipient area might impinge on the activity of neurons in its ventromedial division. Third, alcohol could interfere with protein synthesis, either in a direct way by decreasing mRNA synthesis and translation (Tewari and Noble, 1979) or the rate of polypeptide elongation (Peters and Steele, 1982), or indirectly by interfering with secondary messenger systems (Hunt, 1993 ) or by reducing normal neurotrophic influences (Walker et al., 1993). The view that CET might directly disrupt cellular metabolism in the SCN is strengthened by the striking similarities between the alterations induced by this condition and those attributable to aging. These include a decrease in the number of AVP- and VIP-immunoreactive neurons (Roozendaal et al., 1987; Chee et al., 1988), reduction in neurotransmitter levels (Amenta et al., 1991) and in RNA and protein synthesis (Finch and Morgan, 1990), and changes in intracellular transcription factors reg-

GRP-immunoreactive neurons and fibers is seen in the ventrolateral part of the SCN. The densities of the neurons and fiber plexus are markedly reduced in the ethanol-treated rat $(D)$; the reduction is even more evident in the withdrawn rat $(F)$, which shows the lowest densities of cell bodies and fibers. Scale bars, $50 \mu \mathrm{m}$. G, A GRP-immunoreactive neuron with an intensely stained cytoplasm, a pale nucleus, and a process (arrowhead) arising from its inferior pole. Scale bar, $10 \mu \mathrm{m}$. H, Two GRP-immunoreactive neurons. Processes (arrowheads) can be seen originating from one of the neurons. Scale bar, $10 \mu \mathrm{m}$. I, Graphic representation of the total number of GRP-immunoreactive neurons obtained from the SCN of control $(C)$, ethanol-treated $(E T)$, and withdrawn $(W)$ rats. Horizontal bars represent mean values. $C$ versus $W, p<5 \times 10^{-4}$; $C$ versus $E T, p<0.001 ; E T$ versus $W, p<0.05$. 

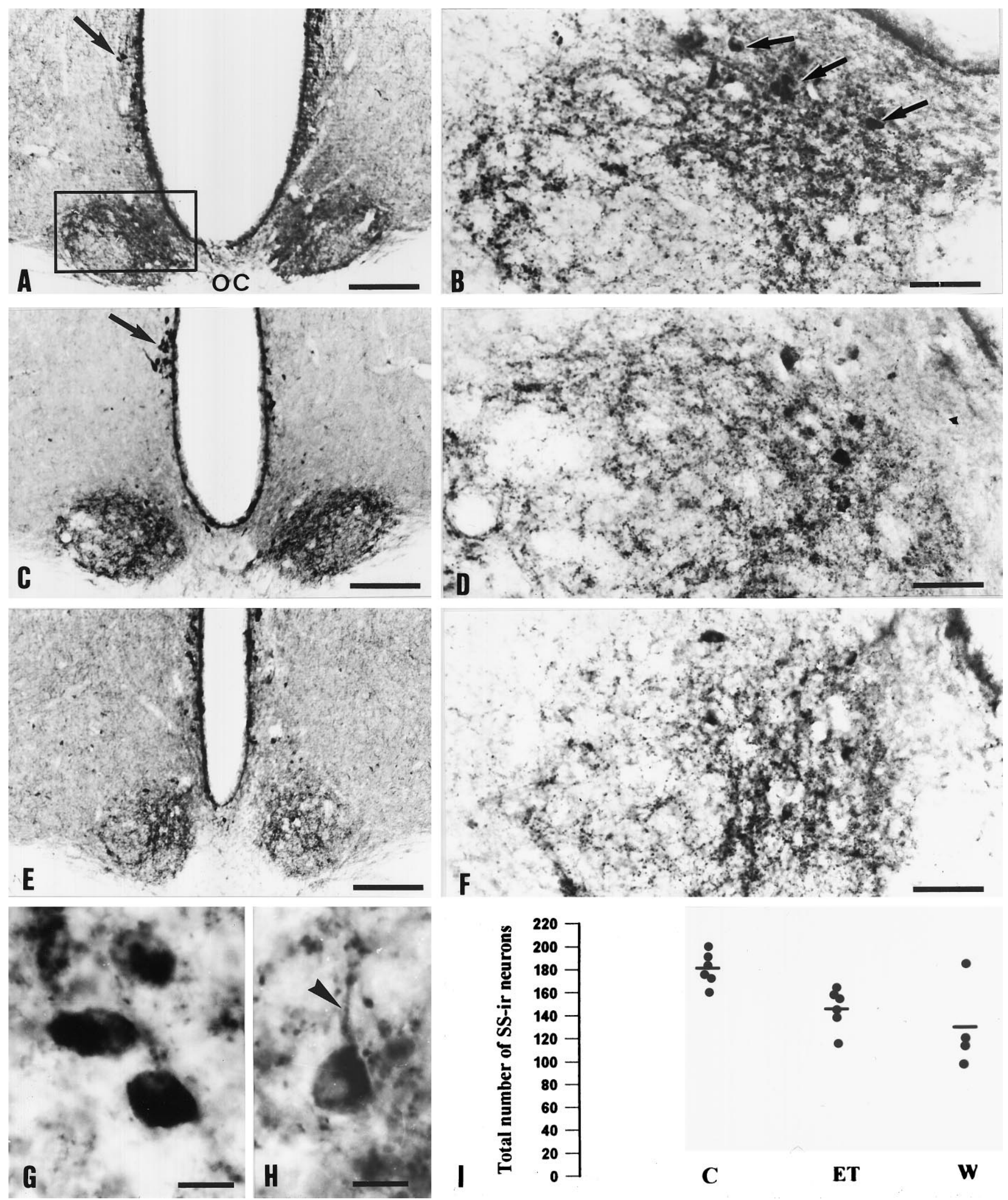

Figure 7. SS immunoreactivity in the SCN of control $(A, B)$, ethanol-treated $(C, D)$, and withdrawn $(E, F)$ rats. $A, C, E$, Photomicrographs of coronal sections through mid-SCN levels. The box illustrated in $A$ delineates the area shown at higher magnification in $B$. The corresponding areas in $C$ and $E$ are shown at higher magnification in $D$ and $F$, respectively. SS-immunoreactive fibers are confined to the SCN, but clusters of SS-immunoreactive neurons (arrows) can be seen in the periventricular zone of the hypothalamus. $O C$, Optic chiasm. Scale bar, $200 \mu \mathrm{m}$. $B, D, F$, Enlargements of the boxed area in $A$ and of the corresponding areas in $C$ and $E$, in the same orientation. The cell bodies (arrows) are confined to the dorsomedial subdivision of the SCN, where SS-immunoreactive fibers are also concentrated. The number of SS-immunoreactive neurons and the density of (Figure legend continues) 

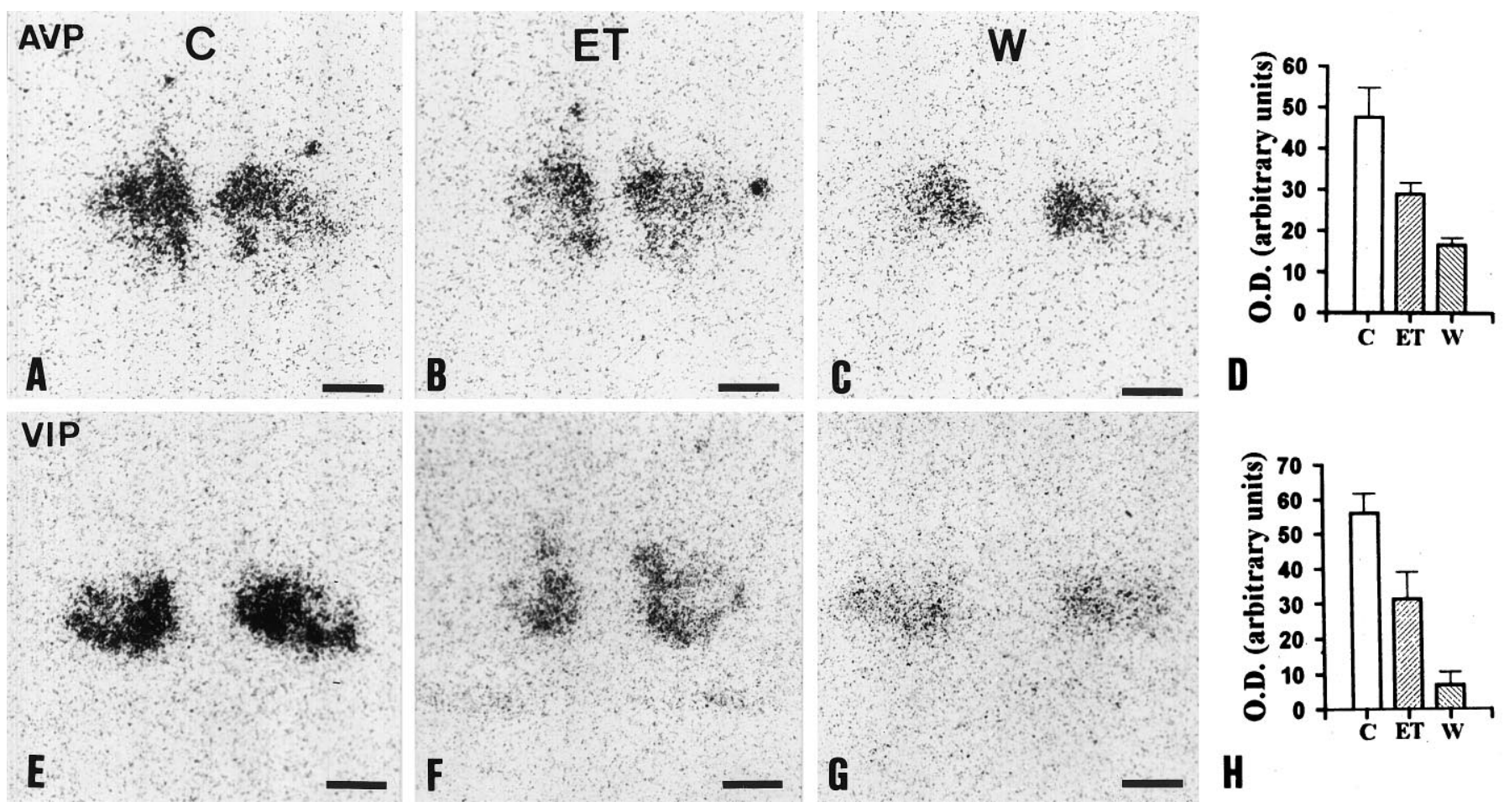

Figure 8. Photomicrographs of hybridization signals from the SCN for AVP $(A-C)$ and VIP $(E-G)$ from representative autoradiograms of control $(A$, $E)$, ethanol-treated $(B, F)$, and withdrawn $(C, G)$ rats. AVP and VIP mRNAs are reduced in the ethanol-treated and withdrawn rats. The withdrawn rat shows the weakest signals for AVP and VIP. $D, H$, Graphic representations of the steady-state levels of mRNAs coding for AVP $(D)$ and VIP $(H)$ in control $(C)$, ethanol-treated $(E T)$, and withdrawn $(W)$ rats. The values are expressed as arbitrary optical density $(O . D$.) units. Columns represent means, and vertical bars represent 1 SD. No statistical analysis was performed on this quantitative data because of the small number of rats analyzed (controls, $n=3$; ethanol-treated, $n=2$; withdrawn, $n=2$ ).

ulating gene expression (Zhang et al., 1996). Finally, the possibility that the alterations found in peptide synthesis and immunoreactivity in the SCN of ethanol-treated rats might simply be a consequence of CET-induced disruption of their daily rhythms cannot be ignored, because the brains used in this study for the immunocytochemical and in situ hybridization analyses were collected at the same time each day, whereas it is known that the mRNAs and peptides analyzed in our study undergo significant circadian changes, particularly between the hours of darkness and light (Inouye and Shibata, 1994). These changes are different, however, for each peptide, and for each peptide there is also a different and specific time lag between the peak level of mRNA expression and the peak peptide content (Inouye and Shibata, 1994). Thus if the changes we have found in mRNA levels and in the numbers of immunoreactive neurons were attributable primarily to a CET-induced disruption in the normal daily rhythms of peptide expression, we would not expect to see either a uniform reduction in these parameters or a similar pattern of change in mRNA levels and numbers of immunoreactive neurons for each of the peptides examined.

If the neurochemical alterations observed during CET were simply to be a consequence of the preponderance of inhibitory versus excitatory inputs on the SCN, one would expect that after withdrawal from alcohol the neurochemistry of the SCN would be restored and the protein synthesis resumed, because under these conditions excitatory neurotransmission would override the inhibitory influences (Lovinger, 1993). Data obtained from withdrawn rats refute this explanation, however, because we found that despite the absence of alterations in the volume and in the total number of neurons, withdrawal leads to a further decay in the total number of AVP, VIP, GRP, and SS neurons. These alterations are attributable to a more serious depression of protein synthesis, because we also show that AVP and VIP mRNA levels decrease further in withdrawn rats than in ethanol-treated rats. These data demonstrate that CET irreversibly damages SCN neurons and that withdrawal represents an additional insult for the SCN, probably because neuronal metabolism had adapted to high levels of ethanol, and withdrawal forces the neurons to make a further major readjustment in their metabolism.

There is evidence that alcohol does not act as a nonspecific depressant of protein synthesis; more specifically, it has been reported that although exposure to ethanol for 1 or 2 weeks decreases AVP mRNA levels in several extrahypothalamic and hypothalamic nuclei (Ishizawa et al., 1990; Gulya et al., 1991; Sanna et al., 1993), including the SCN, after longer periods of alcohol consumption both the synthesis and the content of AVP 
are enhanced in the supraoptic and paraventricular nuclei (Ruela et al., 1994; Carmona-Calero et al., 1995). That alcohol exposure does not lead to a global depression of protein synthesis is further supported by reports showing that after 1 or 4 weeks of alcohol exposure, the mRNA levels of corticotropin releasing hormone and thyrotropin releasing hormone are increased in the paraventricular nucleus (Rivier et al., 1990; Zoeller et al., 1996), such as what has been described for prodynorphin mRNA levels in the hypothalamus (Gulya et al., 1993). Therefore, our data indicate that SCN neurons are a specific target for alcohol, the effects of which are manifested by changes in intracellular metabolism. Furthermore, it may be that the mechanisms underpinning the effects of alcohol withdrawal on SCN neurons are identical to those leading to excitotoxic neurodegeneration in other regions of the brain (McMullen et al., 1984; Phillips and Cragg, 1984; Cadete-Leite et al., 1988, 1990; Paula-Barbosa et al., 1993). For reasons similar to those advanced in relation to the effects of CET on the retinorecipient area of the $\mathrm{SCN}$, this proposal receives additional support from the finding that the withdrawal-associated alterations are particularly marked in the VIP-containing neurons. However, as a result of various protective factors (mentioned above), the toxic effects might not be severe enough to cause cell death but would be sufficient to produce irreversible metabolic damage.

Although the present study leaves open the question of whether CET and withdrawal interfere with the clock mechanism itself, it provides an insight into the effects of ethanol on biological rhythms. The central role of the SCN in the generation of circadian rhythms is well documented, and at least two of the neuropeptides studied here, AVP and VIP, have been implicated in circadian signaling from the SCN to various regions of the brain that are ultimately responsible for the manifestation of behavioral and physiological rhythms. In this study, we used measurements of a robust rhythm, that of corticosterone secretion, to evaluate to what extent CET and alcohol withdrawal influence the diurnal rhythms in the SCN, particularly that of AVP production. The AVP released by SCN neurons exerts inhibitory influences on the synthesis of corticotropin releasing hormone (Kalsbeek et al., 1992). This relationship has been suggested by the observation that the high levels of AVP released from SCN terminals during the light period coincide with the basal plasma levels of corticosterone (Kalsbeek et al., 1996), and by experimental studies, which show that the administration of AVP antagonists or lesions of the SCN result in elevated basal levels of corticosterone in the daytime, during the period when AVP is released from SCN neurons (Kalsbeek et al., 1992, 1996). In light of these data, our observation that the circulating levels of corticosterone were not markedly influenced in any of the treatment groups is surprising, because our immunohistochemical and mRNA hybridization studies show that the activity of SCN neurons is markedly reduced during CET and diminishes further after ethanol withdrawal. This finding is compatible, however, with the view that AVP released from the SCN is not the sole factor accounting for the plasma level of corticosterone. Thus, animals with bilateral lesions of the SCN do not display a continuously high plasma concentration of this hormone (Kalsbeek et al., 1992), and adaptive changes occur in the hypothalamic-pituitary-adrenal axis during CET leading to the development of various degrees of tolerance to ethanol (Spencer and McEwen, 1990; Rivier, 1996). However, the finding that corticosterone levels peak earlier in ethanol-treated rats than in control and withdrawn rats suggests that the circadian rhythms of synthesis and content of SCN peptides (specifically AVP) are likely to be altered by CET, albeit reversibly. In contrast to the mild functional repercussions of the decreased activity of AVPproducing neurons, the alterations induced by CET in reproductive functions and in the circadian pattern of locomotor activity are compatible with the reductions we found in the synthesis and immunoreactivity of VIP. In effect, several studies have shown that decreases in VIP synthesis and release, brought about either by exposure to constant light or as a result of lesions of the SCN, lead to persistent estrous and to a disrupted circadian pattern of locomotor activity (Stobie and Weick, 1990; Aguilar-Roblero et al., 1994; Sollars and Pickard, 1995), alterations that are identical to those observed during CET.

\section{REFERENCES}

Adinoff B, Martin PR, Bone GHA, Eckardt MJ, Roehrich L, George DT, Moss HB, Eskay R, Linnoila M, Gold PW (1990) Hypothalamicpituitary-adrenal axis functioning and cerebrospinal fluid corticotropin releasing hormone and corticotropin levels in alcoholics after recent and long-term abstinence. Arch Gen Psychiatry 47:325-330.

Aguilar-Roblero R, Morin LP, Moore RY (1994) Morphological correlates of circadian rhythm restoration induced by transplantation of the suprachiasmatic nucleus in hamsters. Exp Neurol 130:250-260.

Alfonso M, Durán R, Marcó J (1993) Ethanol-induced alterations in gonadotrophins secretion during the estrous cycle of rats. Alcohol Alcohol 28:667-674.

Amenta F, Zaccheo D, Collier WL (1991) Neurotransmitters, neuroreceptors and aging. Mech Ageing Dev 61:249-273.

Anderson RA, Willis BR, Oswald C (1985) Spontaneous recovery from ethanol-induced male infertility. Alcohol 2:479-484.

Bignami A, Dahl D (1977) Specificity of the glial fibrillary acidic protein for astroglia. J Histochem Cytochem 25:466-469.

Bina KG, Rusak B (1991) Intracranial nerve growth factor injections phase shift activity rhythms in Syrian hamsters. Soc Neurosci Abstr 17:669.

Bonthius DJ, West JR (1990) Alcohol-induced neuronal loss in developing rats: increased brain damage with binge exposure. Alcohol Clin Exp Res 14:107-118.

Bonthius DJ, West JR (1991) Permanent neuronal deficits in rats exposed to alcohol during the brain growth spurt. Teratology 44:147-163.

Brændgaard H, Evans SM, Howard CV, Gundersen HJG (1990) The total number of neurons in the human neocortex unbiasedly estimated using optical disectors. J Microsc 157:285-304.

Buijs RM, Wortel J, Hou Y-X (1995) Colocalization of $\gamma$-aminobutyric acid with vasopressin, vasoactive intestinal peptide, and somatostatin in the rat suprachiasmatic nucleus. J Comp Neurol 358:343-352.

Cadete-Leite A, Tavares MA, Paula-Barbosa MM (1988) Alcohol withdrawal does not impede hippocampal granule cell progressive loss in chronic alcohol-fed rats. Neurosci Lett 86:45-50.

Cadete-Leite A, Tavares MA, Pacheco MM, Volk B, Paula-Barbosa MM (1989) Hippocampal mossy fiber synapses after chronic alcohol consumption and withdrawal. Alcohol 6:303-310.

Cadete-Leite A, Alves MC, Tavares MA, Paula-Barbosa MM (1990) Effects of chronic alcohol intake and withdrawal on the prefrontal neurons and synapses. Alcohol 7:145-152.

Card JP, Moore RY (1984) The suprachiasmatic nucleus of the golden hamster: immunohistochemical analysis of cell and fiber distribution. Neuroscience 13:415-431.

Card JP, Fritzpatrick-McElligott S, Gozes I, Baldino Jr F (1988) Localization of vasopressin-, vasoactive intestinal polypeptide-, peptide histidine isoleucine- and somatostatin-mRNA in rat suprachiasmatic nucleus. Cell Tissue Res 252:307-315.

Carmona-Calero E, Pérez-Delgado MM, Bauelos-Pineda J, MarreroGordillo N, Ferres-Torres R, Castaneyra-Perdomo A (1995) Effects of chronic alcohol intake on the vasopressin content in the hypothalamic paraventricular and supraoptic nuclei of the mouse: an immunocytochemical and morphometric study. Drug Alcohol Depend 38:19-24.

Cavalieri B (1966) Geometria degli indivisibili. Torino: Unione Tipografico Editrice.

Charness ME (1993) Brain lesions in alcoholics. Alcohol Clin Exp Res 17:2-11.

Chee CA, Roozendaal B, Swaab DF, Goudsmit E, Mirmiran M (1988) Vasoactive intestinal polypeptide neuron changes in the senile rat suprachiasmatic nucleus. Neurobiol Aging 9:307-312. 
Cicero TJ, Meyer ER, Bell RD (1979) Effects of ethanol on the hypothalamic-pituitary-luteinizing hormone axis and testicular steroidogenesis. J Pharmacol Exp Ther 208:210-215.

Cintra A, Zoli M, Rosén L, Agnati LF, Okret S, Wikström A-C, Gustafsson J-A, Fuxe K (1994) Mapping and computer assisted morphometry and microdensitometry of glucocorticoid receptor immunoreactive neurons and glial cells in the rat central nervous system. Neuroscience 62:843-897.

Daikoku S, Hisano S, Kagotani Y (1992) Neuronal associations in the rat suprachiasmatic nucleus demonstrated by immunoelectron microscopy. J Comp Neurol 325:559-571.

Davis LG, Arentzen R, Reid JM, Manning RW, Wolfson B, Lawrence KL, Baldino F (1986) Glucocorticoid sensitivity of vasopressin mRNA levels in the paraventricular nucleus of the rat. Proc Natl Acad Sci USA 83:1145-1149.

Decavel C, van den Pol AN (1990) GABA: a dominant neurotransmitter in the hypothalamus. J Comp Neurol 302:1019-1037.

Dees WL, Skelley CW (1990) Effects of ethanol during the onset of female puberty. Neuroendocrinology 51:64-69.

Deimling MJ, Schnell RC (1980) Circadian rhythms in the biological response and disposition of ethanol in the mouse. J Pharmacol Exp Ther 213:1-8.

De Witte P (1996) The role of neurotransmitters in alcohol dependence: animal research. Alcohol Alcohol 31:13-16.

Ding JM, Chen D, Weber ET, Faiman LE, Rea MA, Gillette MU (1994) Resetting the biological clock: mediation of nocturnal circadian shifts by glutamate and NO. Science 266:1713-1717.

Duncan MJ, Cheng X, Heller KS (1995) Photoperiodic exposure and time of day modulate the expression of vasopressin mRNA and vasoactive intestinal peptide mRNA in the suprachiasmatic nuclei of Siberian hamsters. Mol Brain Res 32:181-186.

Ellis FW (1966) Effect of ethanol on plasma corticosterone levels. J Pharmacol Exp Ther 153:121-127.

Finch CE, Morgan DG (1990) RNA and protein metabolism in the aging brain. Annu Rev Neurosci 13:75-87.

Frye GD, Fincher AS (1988) Effect of ethanol on $\gamma$-vinyl GABA-induced GABA accumulation in the substantia nigra and on synaptosomal GABA content in six rat brain regions. Brain Res 449:71-79.

Fukuhara C, Nishiwaki T, Cagampang FRA, Inouye S-IT (1994) Emergence of VIP rhythmicity following somatostatin depletion in the rat suprachiasmatic nucleus. Brain Res 645:343-346.

Gannon RL, Rea MA (1994) In situ hybridization of antisense mRNA oligonucleotides for AMPA, NMDA and metabotropic glutamate receptor subtypes in the rat suprachiasmatic nucleus at different phases of the circadian cycle. Mol Brain Res 23:338-344.

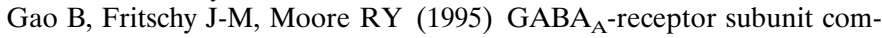
position in the circadian timing system. Brain Res 700:142-156.

Gilliam DM, Collins AC (1983) Circadian and genetic influences on tissue sensitivity and sleep time to ethanol in LS and SS mice. Pharmacol Biochem Behav 18:803-808.

Güldner FH (1983) Numbers of neurons and astroglial cells in the suprachiasmatic nucleus of male and female rats. Exp Brain Res 50:373-376.

Gulya K, Dave JR, Hoffman PL (1991) Chronic ethanol ingestion decreases vasopressin mRNA in hypothalamic and extrahypothalamic nuclei of mouse brain. Brain Res 557:129-135.

Gulya K, Orpana AK, Sikela JM, Hoffman PL (1993) Prodynorphin and vasopressin mRNA levels are differentially affected by chronic ethanol ingestion in the mouse. Mol Brain Res 20:1-8.

Gundersen HJG, Jensen EB (1987) The efficiency of systematic sampling in stereology and its prediction. J Microsc 147:229-263.

Gundersen HJG, Bendtsen TF, Korbo L, Marcussen N, Møller A, Nielsen K, Nyengaard JR, Pakkenberg B, Sørensen FB, Vesterby A, West MJ (1988) Some new, simple and efficient stereological methods and their use in pathological research and diagnosis. APMIS 96:379-394.

Heaton MB, Paiva M, Swanson DJ, Walker DW (1993) Modulation of ethanol neurotoxicity by nerve growth factor. Brain Res 620:78-85.

Hilakivi L, Tuomisto L, Hikalivi I, Kiianmaa K, Hellevuo K, Hyytia P (1987) Effect of prenatal alcohol exposure on neonatal sleep-wake behaviour and adult alcohol consumption in the AA and ANA rat lines. Alcohol Alcohol 22:234-240.

Hu X-J, Follesa P, Ticku MK (1996) Chronic ethanol treatment produces a selective upregulation of the NMDA receptor subunit gene expression in mammalian cultured cortical neurons. Mol Brain Res 36:211-218.

Hunt WA (1993) Neuroscience research: how has it contributed to our understanding of alcohol abuse and alcoholism? A review. Alcohol Clin Exp Res 17:1055-1065.

Inouye S-IT, Shibata S (1994) Neurochemical organization of circadian rhythm in the suprachiasmatic nucleus. Neurosci Res 20:109-130.

Ishizawa H, Dave JR, Liu L-I, Tabakoff B, Hoffman PL (1990) Hypothalamic vasopressin mRNA levels in mice are decreased after chronic ethanol ingestion. Eur J Pharmacol 189:119-127.

Jonas P, Racca C, Sakmann B, Seeburg PH, Monyer H (1994) Differences in $\mathrm{Ca}^{2+}$ permeability of AMPA-type glutamate receptor channels in neocortical neurons caused by differential GluR-B subunit expression. Neuron 12:1281-1289.

Kalsbeek A, Buijs RM, van Heerikhuize JJ, Arts M, van der Woude TP (1992) Vasopressin-containing neurons of the suprachiasmatic nuclei inhibit corticosterone release. Brain Res 580:62-67.

Kalsbeek A, van der Vliet J, Buijs RM (1996) Decrease of endogenous vasopressin release necessary for expression of the circadian rise in plasma corticosterone: a reverse microdialysis study. J Neuroendocrinol 8:299-307.

Kawakami F, Okamura H, Inatomi T, Tamada Y, Nakajima T, Ibata Y (1994) Serotonin depletion by $p$-chlorophenylalanine decreases VIP mRNA in the suprachiasmatic nucleus. Neurosci Lett 174:81-84.

Kiss J, Patel AJ, Halász B (1993) Colocalization of NGF receptor with VIP in rat suprachiasmatic neurones. NeuroReport 4:1315-1318.

Klein DC, Moore RY, Reppert SM (1991) Suprachiasmatic nucleus: the mind's clock. New York: Oxford UP.

Korpi ER (1994) Role of GABA receptors in the actions of alcohol and in alcoholism: recent advances. Alcohol Alcohol 29:115-129.

Laemle LK (1992) Unilateral enucleation alters vasoactive intestinal polypeptide-like immunoreactivity in the suprachiasmatic nucleus of the rat. Brain Res 572:325-328.

Lescaudron L, Seguela P, Geffard M, Verna A (1986) Effects of longterm ethanol consumption on GABAergic neurons in the mouse hippocampus: a quantitative immunocytochemical study. Drug Alcohol Depend 18:377-384.

Lieber CS, DeCarli LM (1982) The feeding of alcohol in liquid diets: two decades of applications and 1982 update. Alcohol Clin Exp Res 6:523-531.

Lovinger DM (1993) Excitotoxicity and alcohol-related brain damage. Alcohol Clin Exp Res 17:19-27.

Madeira MD, Lieberman AR (1995) Sexual dimorphism in the mammalian limbic system. Prog Neurobiol 45:275-333.

Madeira MD, Sousa N, Lieberman AR, Paula-Barbosa MM (1993) Effects of chronic alcohol consumption and of dehydration on the supraoptic nucleus of adult male and female rats. Neuroscience $56: 657-672$.

Madeira MD, Sousa N, Paula-Barbosa MM (1994) Alcohol consumption does not induce cell death in the suprachiasmatic nucleus but reduces the number of vasopressin- and VIP-immunoreactive neurons. Soc Neurosci Abstr 20:348.

Madeira MD, Sousa N, Santer RM, Paula-Barbosa MM, Gundersen HJG (1995) Age and sex do not affect the volume, cell numbers, or cell size of the suprachiasmatic nucleus of the rat: an unbiased stereological study. J Comp Neurol 361:585-601.

Mason GA, Noonan LR, Garbutt JC, Caldwell JD, Shimoda K, Walker CH, Li L, Prange Jr J (1992) Effects of ethanol and control liquid diets on the hypothalamic-pituitary-thyroid axis of male Fischer-344 rats. Alcohol Clin Exp Res 16:1130-1137.

McLane JA (1987) Decreased axonal transport in rat nerve following acute and chronic ethanol exposure. Alcohol 4:385-389.

McMullen PA, Saint-Cyr JA, Carlen PL (1984) Morphological alterations in the rat CA1 hippocampal pyramidal cell dendrites resulting from chronic ethanol consumption and withdrawal. J Comp Neurol 225:111-118.

Meijer JH, Albus H, Weidema F, Ravesloot J-H (1993) The effects of glutamate on membrane potential and discharge rate of suprachiasmatic neurons. Brain Res 603:284-288.

Mick G, Yoshimura R, Ohno K, Kiyama H, Tohyama M (1995) The messenger RNAs encoding metabotropic glutamate receptor subtypes are expressed in different neuronal subpopulations of the rat suprachiasmatic nucleus. Neuroscience 66:161-173.

Mikkelsen JD, Fahrenkrug J (1994) Concentrations and distribution of vasoactive intestinal peptide (VIP), peptide histidine isoleucine (PHI) and peptide histidine valine (PHV) in the cerebral cortex and the suprachiasmatic nucleus of the mouse. Brain Res 656:95-107.

Mikkelsen JD, Larsen PJ, O'Hare MMT, Wiegand SJ (1991) Gastrin 
releasing peptide in the rat suprachiasmatic nucleus: an immunohistochemical, chromatographic and radioimmunological study. Neuroscience 40:55-66.

Mikkelsen JD, Larsen PJ, Ebling FJP (1993) Distribution of $N$-methyl$\mathrm{D}$-aspartate (NMDA) receptor mRNAs in the rat suprachiasmatic nucleus. Brain Res 632:329-333.

Miller MW (1992) Circadian rhythm of cell proliferation in the telencephalic ventricular zone: effect of in utero exposure to ethanol. Brain Res 595:17-24.

Montagne M-N, Dussaillant M, Chew L-J, Berod A, Lamberts SJ, Carter DA, Rostene W (1995) Estradiol induces vasoactive intestinal peptide and prolactin gene expression in the rat anterior pituitary independently of plasma prolactin levels. J Neuroendocrinol 7:225-231.

Moore RY (1983) Organization and function of a central nervous system oscillator: the suprachiasmatic hypothalamic nucleus. Fed Proc 42:2783-2789.

Moore RY, Speh JC (1993) GABA is the principal neurotransmitter of the circadian system. Neurosci Lett 150:112-116.

Morgan MY (1982) Alcohol and the endocrine system. Br Med Bull 8:35-42.

Morin LP (1994) The circadian visual system. Brain Res Rev 67:102-127.

Morin LP, Johnson RF, Moore RY (1989) Two brain nuclei controlling circadian rhythms are identified by GFAP immunoreactivity in hamsters and rats. Neurosci Lett 99:55-60.

Nishizawa M, Hayakawa Y, Yanaihara N, Okamoto H (1987) Nucleotide sequence divergence and functional constraint in VIP precursor mRNA evolution between human and rat. FEBS Lett 183:55-59.

Okamura H, Murakami S, Uda K, Sugano T, Takahashi Y, Yanaihara C, Yanaihara N, Ibata Y (1986) Coexistence of vasoactive intestinal peptide (VIP)-, peptide histidine isoleucine amide (PHI)-, and gastrin releasing peptide (GRP)-like immunoreactivity in neurons of the rat suprachiasmatic nucleus. Biomed Res 8:295-299.

Patchev VK, Hayashi S, Orikasa C, Almeida OFX (1995) Implications of estrogen-dependent brain organization for gender differences in hypothalamo-pituitary-adrenal regulation. FASEB J 9:419-423.

Paula-Barbosa MM, Tavares MA (1985) Long term alcohol consumption induces microtubular changes in the adult rat cerebellar cortex. Brain Res 339:195-199.

Paula-Barbosa MM, Borges MM, Cadete-Leite A, Tavares MA (1986) Giant multivesicular bodies in the rat hippocampal pyramidal cells after chronic alcohol consumption. Neurosci Lett 64:345-349.

Paula-Barbosa MM, Brandão F, Madeira MD, Cadete-Leite A (1993) Structural changes in the hippocampal formation after long-term alcohol consumption and withdrawal in the rat. Addiction 88:237-247.

Pentney RJ, Quigley PJ (1987) Morphometric parameters of Purkinje dendritic networks after ethanol treatment during aging. Alcohol Clin Exp Res 11:536-540.

Peters JE, Steele WJ (1982) Changes in in vivo rates of protein synthesis on free and membrane-bound polysomes in rat brain during the development of physical dependence on ethanol and after the withdrawal of ethanol. Brain Res 231:411-426.

Peterson GM, Moore RY (1980) Selective effects of kainic acid on diencephalic neurons. Brain Res 202:165-182.

Phillips SC, Cragg BG (1984) Alcohol withdrawal causes a loss of cerebellar Purkinje cells in mice. J Stud Alcohol 45:475-480.

Prosser RA, Edgar DM, Heller HC, Miller JD (1994) A possible glial role in the mammalian circadian clock. Brain Res 643:296-301.

Przewlocki R, Hassan AHS, Lason W, Epplen C, Herz A, Stein C (1992) Gene expression and localization of opioid peptides in immune cells of inflamed tissue: functional role in antinociception. Neuroscience 48:491-500.

Rivier C (1996) Alcohol stimulates ACTH secretion in the rat: mechanisms of action and interactions with other stimuli. Alcohol Clin Exp Res 20:240-254.

Rivier C, Imaki T, Vale W (1990) Prolonged exposure to alcohol: effect on CRF mRNA levels, and CRF- and stress-induced ACTH secretion in the rat. Brain Res 520:1-5.

Rivier C, Rivest S, Vale W (1992) Alcohol-induced inhibition of LH secretion in intact and gonadectomized male and female rats: possible mechanisms. Alcohol Clin Exp Res 16:935-941.

Roozendaal B, van Gool WA, Swaab DF, Hoogendijk JE, Mirmiran M (1987) Changes in vasopressin cells of the rat suprachiasmatic nucleus with aging. Brain Res 409:259-264.

Ruela C, Sousa N, Madeira MD, Paula-Barbosa MM (1994) Stereological study of the ultrastructural changes induced by chronic alcohol consumption and dehydration in the supraoptic nucleus of the rat hypothalamus. J Neurocytol 23:410-421.

Rusak B, Zucker I (1979) Neural regulation of circadian rhythms. Physiol Rev 59:449-526.

Sanna PP, Folsom DP, Barizo MJ, Hirsch MD, Melia KR, MaciejewskiLenoir D, Bloom FE (1993) Chronic ethanol intake decreases vasopressin mRNA content in the rat hypothalamus: a PCR study. Mol Brain Res 19:241-245.

Selim M, Glass JD, Hauser UE, Rea MA (1993) Serotoninergic inhibition of light-induced fos protein expression and extracellular glutamate in the suprachiasmatic nuclei. Brain Res 621:181-188.

Senut M-C, Lamour Y, Lee J, Brachet P, Dicou E (1990) Neuronal localization of the nerve growth factor precursor-like immunoreactivity in the rat brain. Int $\mathrm{J}$ Dev Neurosci 8:65-80.

Shanley BC, Wilce PA (1993) Receptor changes associated with ethanolinduced brain damage. In: Alcohol-induced brain damage (Hunt WA, Nixon SJ, eds), pp 299-324. Rockville: NIH Publication No. 93-3549.

Shinohara K, Tominaga K, Isobe Y, Inouye S-IT (1993) Photic regulation of peptides located in the ventrolateral subdivision of the suprachiasmatic nucleus of the rat: daily variations of vasoactive intestinal polypeptide, gastrin-releasing peptide, and neuropeptide Y. J Neurosci 13:793-800.

Simerly RB, Chang C, Muramatsu M, Swanson LW (1990) Distribution of androgen and estrogen receptor mRNA-containing cells in the rat brain: an in situ hybridization study. J Comp Neurol 294:76-95.

Sofroniew MV, Weindl A (1980) Identification of parvocellular vasopressin and neurophysin neurons in the suprachiasmatic nucleus of a variety of mammals including primates. J Comp Neurol 193:659-675.

Sollars PJ, Pickard GE (1995) Vasoactive intestinal peptide efferent projections of the suprachiasmatic nucleus in anterior hypothalamic transplants: correlation with functional restoration of circadian behavior. Exp Neurol 136:1-11.

Spencer RL, McEwen BS (1990) Adaptation of the hypothalamicpituitary-adrenal axis to chronic ethanol stress. Neuroendocrinology 52:481-489.

Srkalovic G, Selim M, Rea MA, Glass JD (1994) Serotoninergic inhibition of extracellular glutamate in the suprachiasmatic nuclear region assessed using in vivo brain microdialysis. Brain Res 656:302-308.

Stobie KM, Weick RF (1990) Effects of lesions of the suprachiasmatic and paraventricular nuclei on the inhibition of pulsatile luteinizing hormone release by exogenous vasoactive intestinal peptide in the ovariectomized rat. Neuroendocrinology 51:649-657.

Sundberg DK, Bo WJ, Reilly J (1987) Effect of chronic alcohol consumption on the pregnant mare serum gonadotrophin-induced luteinizing hormone surge. Neuroendocrinology 46:283-288.

Swaab DF, Slob AK, Houtsmuller EJ, Brand T, Zhou JN (1995) Increased number of vasopressin neurons in the suprachiasmatic nucleus (SCN) of "bisexual" adult male rats following perinatal treatment with the aromatase blocker ATD. Dev Brain Res 85:273-279.

Tabakoff B, Jaffe RC, Ritzmann RF (1978) Corticosterone concentrations in mice during ethanol drinking and withdrawal. J Pharm Pharmacol 30:371-374.

Tavares MA, Paula-Barbosa MM, Gray EG (1983) A morphometric Golgi analysis of the Purkinje cell dendritic trees after long-term alcohol consumption in the adult rat. J Neurocytol 12:939-948.

Tavares MA, Paula-Barbosa MM, Cadete-Leite A (1987) Chronic alcohol consumption reduces the cortical layer volumes and the number of neurons of the rat cerebellar cortex. Alcohol Clin Exp Res 11:315-319.

Tewari S, Noble EP (1979) Effects of ethanol on cerebral protein and ribonucleic acid synthesis. In: Biochemistry and pharmacology of ethanol. (Majchrowicz E, Noble EP, eds), pp 541-548. New York: Plenum.

Tremwel MF, Hunter BE, Peris J (1994) Chronic ethanol exposure enhances $\left[{ }^{3} \mathrm{H}\right] \mathrm{GABA}$ release and does affect $\mathrm{GABA}_{\mathrm{A}}$ receptor mediated ${ }^{36} \mathrm{Cl}$ uptake. Synapse 17:149-154.

Uhl GR, Reppert SM (1986) Suprachiasmatic nucleus vasopressin messenger RNA: circadian variation in normal and Brattleboro rats. Science 232:390-393.

van den Pol AN (1980) The hypothalamic suprachiasmatic nucleus of rat: intrinsic anatomy. J Comp Neurol 191:661-702.

van den Pol AN, Dudek FE (1993) Cellular communication in the circadian clock, the suprachiasmatic nucleus. Neuroscience 56:793-811.

van den Pol AN, Tsujimoto KL (1985) Neurotransmitters of the hypothalamic suprachiasmatic nucleus: immunocytochemical analysis of 25 neuronal antigens. Neuroscience 15:1049-1086.

van den Pol AN, Finkbeiner SM, Cornell-Bell AH (1992) Calcium excit- 
ability and oscillations in suprachiasmatic nucleus neurons and glia in vitro. J Neurosci 12:2648-2664.

Walker DW, Hunter BE, Abraham WC (1981) Neuroanatomical and functional deficits subsequent to chronic ethanol administration in animals. Alcohol Clin Exp Res 5:267-282.

Walker DW, Heaton MB, Lee N, King MA, Hunter BE (1993) Effects of chronic ethanol on the septohippocampal system: a role for neurotrophic factors? Alcohol Clin Exp Res 17:12-18.

Wang X, Dayanithi G, Lemos JR, Nordmann JJ, Treistman SN (1991) Calcium currents and peptide release from neurohypophysial terminals are inhibited by ethanol. J Pharmacol Exp Ther 259:705-711.

West MJ, Slomianka L, Gundersen HJG (1991) Unbiased stereological estimation of the total number of neurons in the subdivisions of the rat hippocampus using the optical fractionator. Anat Rec 231:482-497.

Zhang Y, Kornhauser JM, Zee PC, Mayo KE, Takahashi JS, Turek FW (1996) Effects of aging on light-induced phase-shifting of circadian behavioral rhythms, Fos expression and CREB phosphorylation in the hamster suprachiasmatic nucleus. Neuroscience 70:951-961.

Zhou L, Blaustein JD, De Vries G (1994) Distribution of androgen receptor immunoreactivity in vasopressin- and oxytocin-immunoreactive neurons in the male rat brain. Endocrinology 134:2622-2627.

Zoeller RT, Fletcher DL, Simonyi A, Rudeen K (1996) Chronic ethanol treatment reduces the responsiveness of the hypothalamic-pituitarythyroid axis to central stimulation. Alcohol Clin Exp Res 20:954-960. 